C2020. Licensed under the Creative Commons Attribution-NonCommercial-NoDerivatives 4.0 International http://creativecommons.org/about/downloads

(c) (1) $(9$ BY NC ND

Published at https://doi.org/10.1016/j.tws.2020.106673 


\title{
Numerical and experimental investigation of impact on bilayer aluminum- rubber composite plate
}

\author{
Amin Khodadadi ${ }^{1}$, Gholamhossein Liaghat ${ }^{1,2 *}$, Davoud Shahgholian-Ghahfarokhi ${ }^{1}$, \\ Mahmoud Chizari ${ }^{3}$, Bin Wang ${ }^{4}$ \\ ${ }^{1}$ Department of Mechanical Engineering, Tarbiat Modares University, Tehran, Iran \\ ${ }^{2}$ Department of Mechanical Engineering, Kingston University, London, United Kingdom \\ ${ }^{3}$ School of Engineering and Technology, University of Hertfordshire, Hatfield, United Kingdom \\ ${ }^{4}$ Departement Mechanical andAerospace Engineering, University of Brunel, London, United Kingdom \\ * Corresponding author, Ghlia530@modares.ac.ir and G.Liaghat@kingston.ac.uk
}

\begin{abstract}
This paper aims to investigate the performance of an aluminum-rubber composite plate under impact loading. The impact resistance of the plate has been evaluated using both experimental and numerical methods. The experimental testswerecarried out using gas gun at velocities of 75, 101, 144 and $168 \mathrm{~m} / \mathrm{s}$. The energy absorption of composite plates has been closely examined for all samples. The effect of rubber layer positioning either on front face or onback face of the aluminum plate was also evaluated.It was found that the composite plate with rubber on front face provides higher performance to absorb the energy. In parallel to the experiment, a finite element model was created using the finite element software LS-DYNA to simulate the response of the aluminum-rubber composite plate under a high energy rate loading condition. The data obtained from finite element modeling shown a close agreement with the experimental results in terms of failure mechanism and energy absorption.In addition, a parametric study was carried out incorporating different impact velocities, rubber formulation, rubber layer thickness, interface bonding strength between rubber and aluminum layers and ballistic performance of aluminum-rubber sandwich panel.It was concluded that by increasing the rubber layer's thickness the energy absorption of the composite plate will be increased, especially when rubber layer placed in front face of the aluminum plate. Although athighinterface bonding of rubber and aluminum layer, the composite with rubber layer in front face has better performance, but low bondingof interfacelead to higher energy absorption in back face configuration.
\end{abstract}

Keywords:Impact loading;Numerical simulation; LS-DYNA;Energy absorption; Bilayer aluminumrubber composite. 


\section{Introduction}

The protection capability of armor plates made of strong aluminum alloys has been a topic of interest for many years due to their low density, reasonable formability and high impact strength. Many publications deal with the ballistic performance of aluminum plates under impact of projectile through experimental and numerical analysis [1-5].

In recent years, researchers have made significant efforts to improve the performance of metallic structural protectionsagainst impact threats[6-8]. One major development has been theuse of elastomeric coatings on hard substrates to decrease the damages of blast loadand penetration of projectiles.Elastomers can beused todissipate kinetic energy associated with impacts and shocks. Due to ability of absorption of considerable amount of energy before failure elastomers have been considered as a protective coating for structural and composite system under dynamic loading induced by blast, ballistic and other impact events. Several elastomers have been shown promising results in theseapplications. Amini et al. [9, 10] investigated the response of monolithic steel plates and steel-polyureabilayer plates subjected to impulsive and direct pressure pulse. The research was carried outexperimentally and numerically,focusing on the deformation and failure modes of the plates. Their results suggested that the polyurea layer can have a significant effect on the response ofthe steel plate onto dynamic impulsive loads. They have considered the failure mitigation and energy absorption of the plate, if the layer attached on the back face of the plate.Roland et al.[11, 12] reported the ability of polyurea coatings to increase the impact resistance of high hardness steel plates, where they observed the effect of different layer configurations on the residual velocity. They showed that when polyurea applied to the strike face of steel plates provides a significant enhancement in the ballistic resistance of these plates. They have concluded that 
the most possiblereason for this improvement against impact resistance of the polyurea-coated steel is a phase transition of the polyurea from the rubbery phase to the glassy phase.This hypothesis was supported by Grujicic [13]using a computational modelto evaluate the energy absorption when a deformation-induced glass transition occurs.

Natural rubber (NR) is an appropriate material which can be used as a layer on arigid substrate.Rubber materials have been widely used in shock absorbers, impact resistance panels and other engineering applications [14, 15].High level of damping property[16],high level of flexibility[17], and excellent puncture and tear resistance[18] are the specific properties of NR. These features make NRa good candidateto be used as reinforcement in acomposite structure[19-22].To convert a raw NR into a material with desired properties, some ingredients such as fillers, activators, sulfur or other equivalent curatives and accelerators should be added to the raw NR. Variation of compound ingredients alters themechanical properties of rubber [23]. These additives modify the rubber by forming cross-links between polymer chains. One of the most important ingredientsis fillerincluding carbonblack and calcium carbonate[24-26]. These fillers are added to rubber formulation to improve the mechanical properties of NR.

As highlighted above, although there are some researches investigated the impact response of metallic plates coated by polyuria elastomer butimpact response of bilayer aluminumrubber composite is not investigated yet. Therefore, there is a knowledge gap in this area to understand the effect of the rubber panel on the energy absorption of an aluminumplate.In order to explore the ballistic performance of these composites, experimental studies were conductedusing hemispherical projectileswith impact velocities of $75,101,144 \mathrm{~m} / \mathrm{s}$ and168 $\mathrm{m} / \mathrm{s}$.During the experiments, the focus was on the significance of positioning the rubber layer onto the front face or onto the back face of the aluminum plate.Intention was to look for 
probable configuration of bilayer aluminum-rubber composite which provides more energy absorption.In parallel,the failure mode of layerwas closely monitored and the observation was mimicked to create a computer simulation. The numerical modelwas then used to carry a series of parametric studies to investigate the parameters which affect the impact resistance of bilayer aluminum-rubber composite.

\section{Experimental procedure}

\subsection{Materials and specimen preparation}

Aluminum alloy has been used as a candidate material in many engineering applications due to its low density and high ductility and its reasonable strength. In this study, Aluminum 2024-T3 was used to carry the experimental tests. The stress-strain curve of Aluminum 2024-T3,which was obtainedfromtensile test,was shown in Fig 1 and its mechanical properties were reported in Table 1.

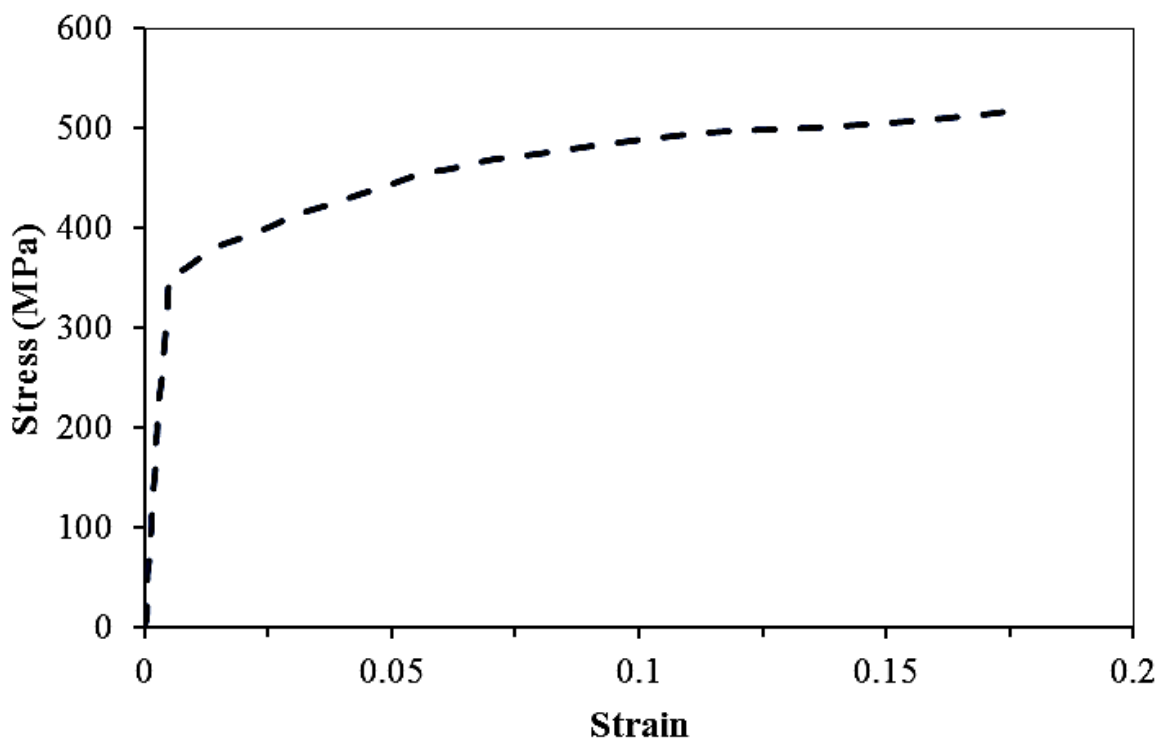

Fig. 1 Tensile stress-strain curve of aluminum 2024-T3 
Table 1 Mechanical properties of aluminum 2024-T3

\begin{tabular}{lc}
\hline Property & Value \\
\hline Density, $\rho\left(\mathrm{kg} / \mathrm{m}^{3}\right)$ & 2700 \\
Elastic modulus, E $(\mathrm{MPa})$ & 72200 \\
Yield stress, $\sigma_{y}(\mathrm{MPa})$ & 350 \\
Poisson ratio, $v$ & 0.32 \\
$\varepsilon_{\mathrm{f}}$ & 0.18 \\
\hline
\end{tabular}

Natural rubber (SMR 20) with Mooney viscosity of 65 was used to carry the experiments in this study. The SMR 20 material was supplied by the Rubber Research Institute of Malaysia. Compound ingredients named fillers such as carbon black and calcium carbonatewereadded to the rubber formulation to improve its mechanical properties. In rubber compound, $\mathrm{ZnO}$, stearic acid, accelerators and sulfur constitute the vulcanization system whichis used for crosslinking of the matrix phase. To evaluate the behavior of rubber with different components at high strain rates, two types of rubber with different formulation were used. The NR compounds formulation for two types of compounds with high hardness (HH) and low hardness (LH) is presented in Table 2.Compounding were performed on an open two-roll mixing mill (Polymix $200 \mathrm{~L}$, Germany) and were cured under hydraulic pressure according to the rheometer results which is presented in Fig.2 for both $\mathrm{LH}$ and $\mathrm{HH}$ rubber.

Table 2 Formulation of the rubber compounds

\begin{tabular}{lcc}
\hline \multirow{2}{*}{ Ingredients } & \multicolumn{2}{c}{ Loading (Phr) } \\
& Formulation 1 & Formulation 2 \\
\hline NR & 100 & 100 \\
Carbon Black (N330) & 60 & 40 \\
Zink oxide & 5 & 5 \\
Calcium carbonate & 30 & 30 \\
Spindle oil & 15 & 30 \\
Sulfur & 2 & 1.5 \\
Volcacit & 0.7 & 0.7 \\
\hline
\end{tabular}




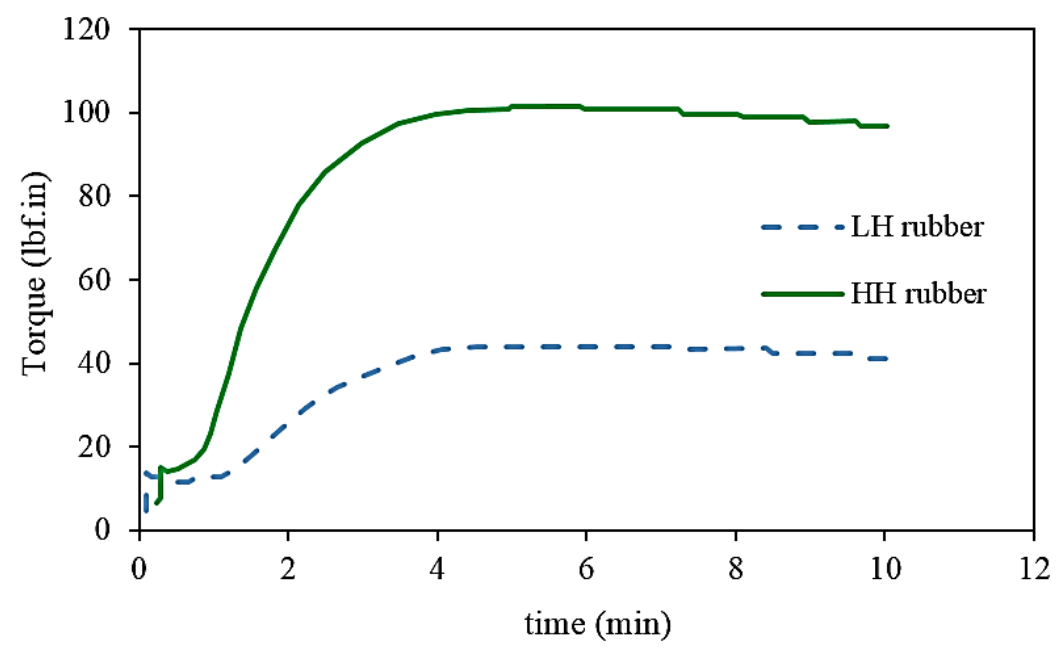

Fig. 2 Rheometer curves

To prepare the specimens, a layer of aluminum with thickness of $0.5 \mathrm{~mm}$ and rubber layer with $2 \mathrm{~mm}$ were bonded together by BYLAMET S2 adhesive. Before bonding, the aluminum plate was carefully cleaned using acetone. To obtain a strong bonding between aluminum and rubber plates, a pressure was applied on the specimen. Fig. 3 shows the bilayer aluminumrubber specimen and its dimensions.

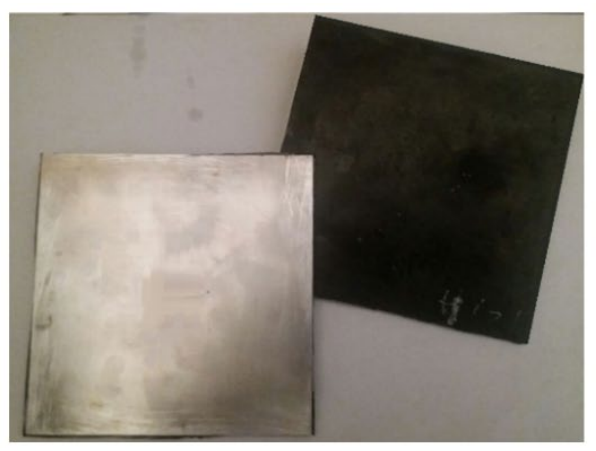

(a)

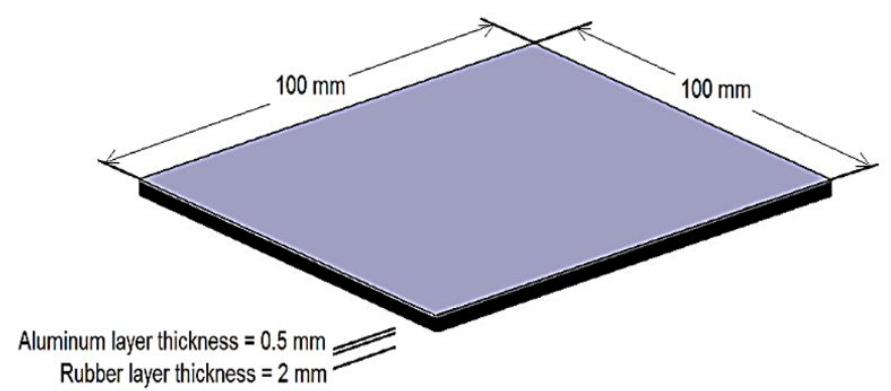

(b)

Fig. 3 (a) Aluminum-rubber specimens (b) Dimension of specimens

\subsection{Impact tests}

Impact tests were performed using a gas gunas shown in Fig. 4. The gas gun was made of a pressure vessel with 120 bar capacity, a high speed firing valve and a hollow steel barrel with 
$6 \mathrm{~m}$ long. The inside diameter of barrelwas $10 \mathrm{~mm}$. The exact impact velocity of each projectile was measured with a chronograph (model M-1, Chrony Canada) before and after impacting the target. Fixture for holding the specimenswas located in the target chamber. The projectile used for ballistic tests was made of steel and were hardened by heat treatment to minimize projectiles' deformation. The physical properties of projectile were presented in table 3 .
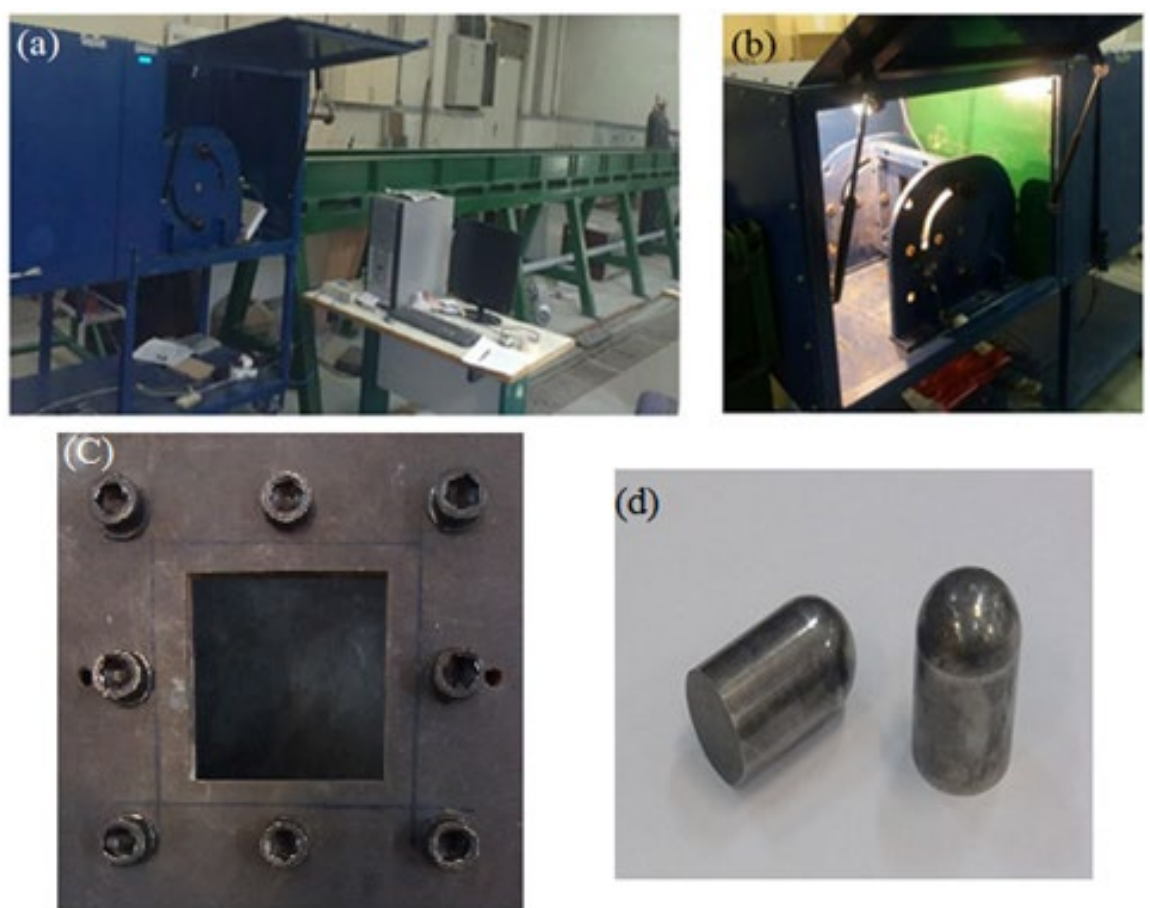

Fig. 4 (a) Gas gun (b) Target chamber (c) Fixture (d) Projectiles

Table 3 Physical properties of projectile

\begin{tabular}{cccc}
\hline Length $(\mathrm{mm})$ & Diameter $(\mathrm{mm})$ & Weight $(\mathrm{g})$ & Hardness $(\mathrm{RC})$ \\
\hline 16.75 & 10 & 9.32 & $55-56$ \\
\hline
\end{tabular}

\subsection{SHPB experiment}

High strain rate tests on the rubber sample were conducted using Split Hopkinson Pressure Bar (SHPB) to obtain the samples stress-strain properties at different strain rates. The conventional 
steel SHPB helps to test metallic materials, but it cannot precisely determine the dynamic responses of soft materials like rubber [27]. The tests were performed using nylon bars instead of metal bar owing to this limitation. The mechanical impedance of nylon bars is much closer to that of the rubber specimens. Thus, the transmitted wave is sufficiently large for measurement. The Split Hopkinson Pressure Bar (SHPB) system, striker bar and rubber specimen are presented in Fig. 5. The ratio of optimal length-to-diameter (L/D) in the specimens for the SHPB test is 0.5, which was used to minimize inertia and friction effects [28].To ensure homogeneous deformation and stress equilibrium during the experiment, the length of soft material specimens must be sufficiently short. In this study, the length of the specimen was designed to be $5 \mathrm{~mm}$.

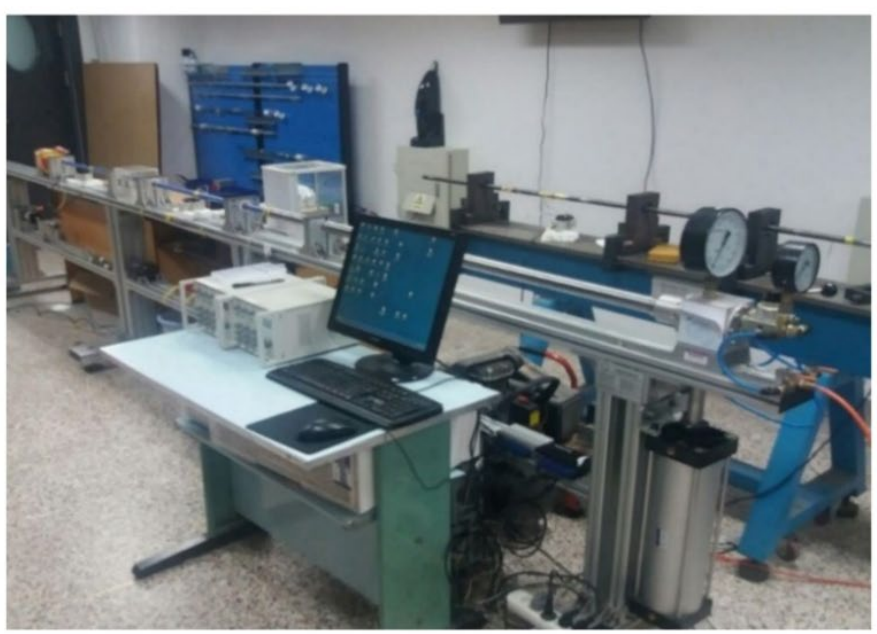

(a)

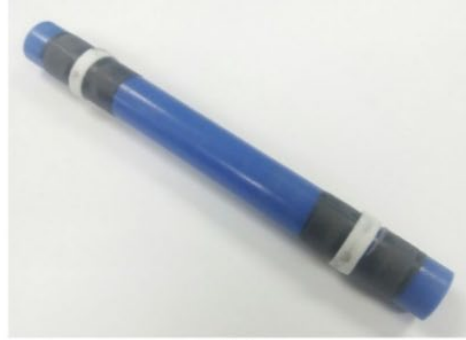

(b)

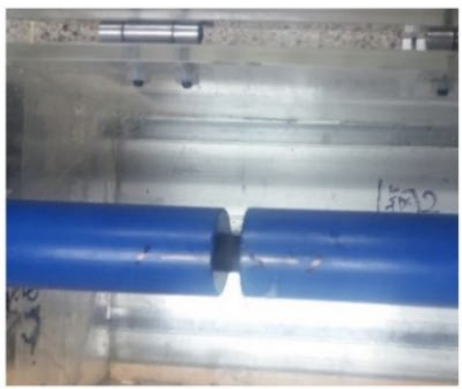

(c)

Fig. 5 Split Hopkinson Pressure Bar test (a) SHPB machine (b) Strikerbar (c) rubber Specimen.

\section{Numerical analysis}

\subsection{Geometry modelling}

The commercial finite element software, LS-DYNA V9.71, was used to simulate the response of aluminum-rubber composite under impact loading. LS-DYNA is a non-linear dynamic 
modeling software that benefits explicit formulation. The numerical model consists of a projectile with initial velocity and a bilayer aluminum-rubber composite plate. Fig. 6shows the finite element model of projectile and target for rubber layer located on the impact face (front face; FF) and second the rubber layer located on the face opposite to the impact side (back face; BF). aluminum-rubber composite was modeled with the dimensions of $100 \times 100 \mathrm{~mm}$. Clamped boundary condition was assigned to the model to restrict all degrees of freedom at edges as shown in Fig. 6(c). To include out-plane stress components, the composite model was meshed with 8-node reduced integration solid element. Mesh sensitivity was checked by varying the number of the elements along the bilayer aluminum-rubber composite thickness to obtain the residual velocity of projectile with adequate accuracy. The mesh of bilayer plate included a total number of 400000 elements. 160000 elements in aluminum layer with the mesh size of $0.5 \times 0.5 \times 0.125 \mathrm{~mm}$ and 240000 elements with the mesh size of $0.5 \times 0.5 \times 0.33$ mmfor rubber layer. Also the projectile's mesh had 12900 elements.

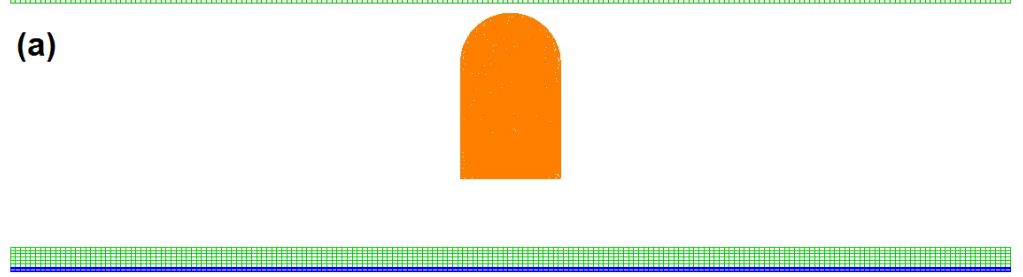

(b)

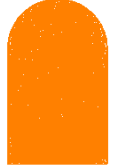

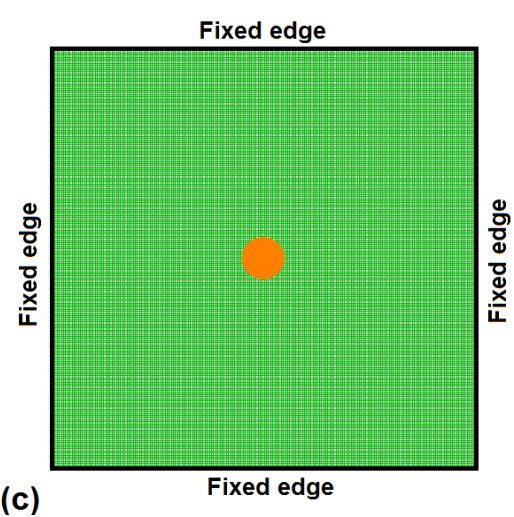

Fig. 6 Finite element model (a) rubber layer located on the impact face (b) rubber layer located on the opposite of the impact face (c) Boundary conditions 


\subsection{Material modeling}

\subsubsection{Aluminum plate}

Material model 3 in LS-DYNA software (MAT_PLASTIC_KINEMATIC) was chosento describe elastic-plastic behavior of the aluminum plate. This material model uses an isotropic constitutive based on isotropic and kinematic hardening [29]. Also, strain rate effects are estimated by Cowper-Symonds constitutive relationship.

$$
\sigma_{y-d y n}=\left[1+(\dot{\varepsilon} / c)^{1 / P}\right]\left(\sigma_{y-s t}+E_{P} \mathcal{E}_{P}\right)
$$

In Eq. (1), $\mathrm{P}$ and $\mathrm{C}$ are empirical constants, and for aluminum alloys are 4 and $6500 \mathrm{1} / \mathrm{s}$, respectively [30, 31]. Also, $\mathrm{E}_{\mathrm{p}}$ is calculated as shown in Eq. (2).

$$
E_{p}=E E_{t} /\left(E-E_{t}\right)
$$

Where $\mathrm{E}_{\mathrm{t}}$ is tangent modulus of bilinear stress-strain curve.

The plastic-kinematic material model which was used with Cowper-Symonds constitutive relationship, is an appropriate to model the failure and fracture of aluminum plate. Fracture strain was considered as criteria to model failure. As the projectile hits the aluminum plate its nose pushes the front surface of it which caused generation of compressive stress at the target surface. Further movement of the projectile created the tensile stretching of the material due to which thinning of the material was observed particularly close to contact region between the target and the projectile. Finally, by exceeding the element strain from fracture strain, the element is deleted from simulation.

\subsubsection{Rubber layer}


LS-DYNA offers several material models of rubber-like materials. In this research MooneyRivlin model has been chosen which the strain energy function is given by:

$$
W=C_{10}\left(I_{1}-3\right)+C_{01}\left(I_{2}-3\right)
$$

Where $\mathrm{I}_{1}$ and $\mathrm{I}_{2}$ are the principal invariants of the left Cauchy-Green deformation tensor, defined by:

$$
\begin{aligned}
& I_{1}=\operatorname{tr} C=\lambda_{1}{ }^{2}+\lambda_{2}{ }^{2}+\lambda_{3}{ }^{2} \\
& I_{2}=\frac{1}{2}\left[(\operatorname{tr} C)^{2}-\operatorname{tr}^{2}\right]=\lambda_{1}{ }^{2} \lambda_{2}{ }^{2}+\lambda_{1}{ }^{2} \lambda_{3}{ }^{2}+\lambda_{2}{ }^{2} \lambda_{3}{ }^{2} \\
& I_{3}=\operatorname{det} C=\lambda_{1} \lambda_{2} \lambda_{3}
\end{aligned}
$$

Where $\lambda_{1}, \lambda_{2}$ and $\lambda_{3}$ are the principal stretches. The Mooney-Rivlin model does not take the strain rate effect into consideration. However, with certain adjustment, the Mooney-Rivlin model can be used in the simulations. Fig. 7 shows the stress-strain curves at different strain rates obtained by SHPB tests for two $\mathrm{LH}$ and $\mathrm{HH}$ natural rubber. The strain rate that the material undergoes during the penetration process was estimated by impact simulation on pure rubber panel. The study used the strain rate about $4000 \mathrm{~s}^{-1}$ for the rubber and fitted it with Mooney-Rivlin material model, using least squares approach. The calibrated coefficients of $\mathrm{C}_{10}$ and $\mathrm{C}_{01}$ are 5.6 and 0.5 , respectively for $\mathrm{HH}$ rubber and 2.9 and 0.4 for $\mathrm{LH}$ rubber. The maximum principal strain is used as the failure criterion of the rubber. The pure rubber panel was modeled by LS-DYNA and impact response of panel was simulated and verified by the authors' pervious experimental work [32]. Although, results of quasi-static test show the HH and $\mathrm{LH}$ rubber strain to break are about 2.2and 3.5under quasi-static test but from a series of simulations, it was estimated that the fracturestrain for the rubber material is 1.20 and 1.70 under high strain rate. Split Hopkinson pressure bar results show that in high strain rates, rubber material behaves stiffer. It can be seen that by increasing the strain rate, the strain-stress 
curve transfers to higher values, which means higher stiffness. On the other hand, it was shown by Roland [11], when an elastomer was loaded in high strain rates, its behavior transfers from elasticity to brittle behavior. This means its elongation capacity decreases and rubber fails at lower strain values.
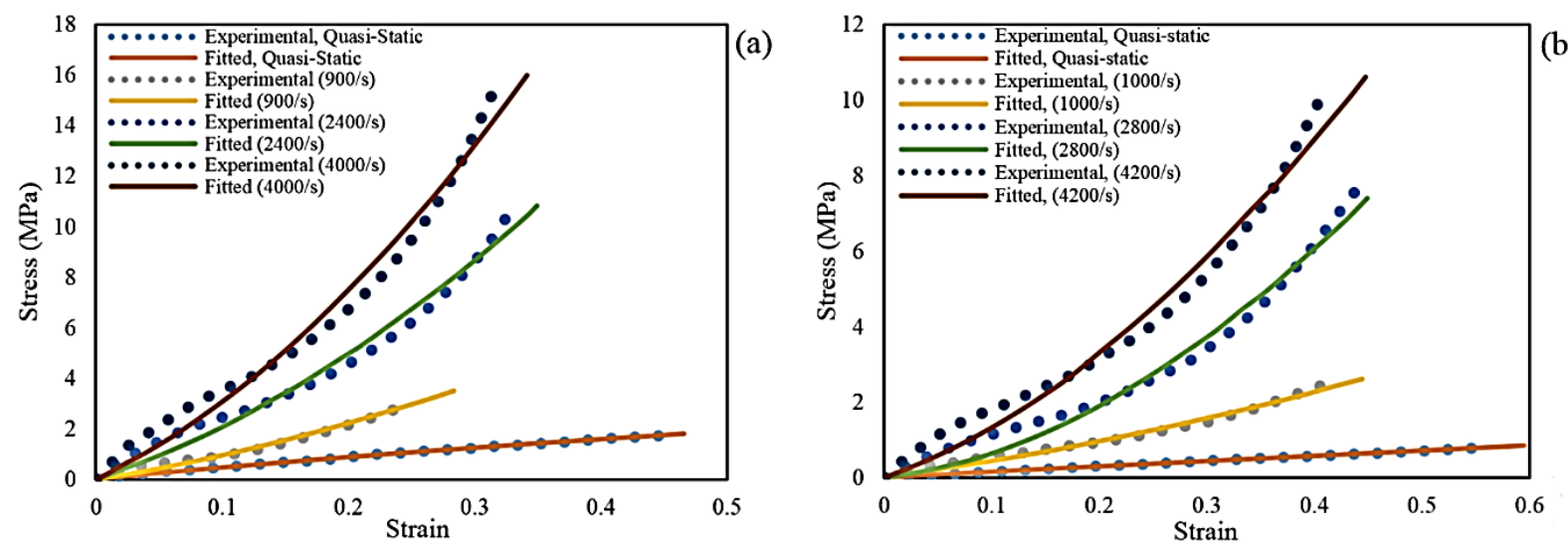

Fig. 7 Stress-Strain curves of rubber at different strain rates (a) high hardness rubber (b) low hardness rubber

\subsection{Contact modeling}

To allow the removing of elements due to the impact of projectile, CONTACT_ERODING_SURFACE_TO_SURFACE was added between the projectile and target layers. Also results of impact tests on bilayer aluminum-rubber composite indicated that debonding is an important failure mode. This fact led to the necessity to implement debonding in the modelling of composite. Debonding in LS-DYNA was modeled through the TIEBREAK_SURFACE_TO_SURFACE contact algorithm. Tiebreak is active for nodes which are initially in contact. This contact algorithm incorporates failure criteria that, when achieved, release the tied interface between the contacting faces and the constraint is transformed to surface-to-surface contact that allows sliding between the faces while 
preventing the penetration of nodes between the parts in contacts. Debonding occurs when the following equation is satisfied:

$$
\left(\frac{\sigma}{N F L S}\right)^{2}+\left(\frac{\tau}{S F L S}\right)^{2} \geq 1
$$

Where $\sigma$ and $\tau$ are the normal and shear stresses at theinterface, and SFLS and NFLS are the interface normal and shearingstrengths. Because there was no any bonding strength experimental data at the time, a trial and error method was employed to reproduce the experimentally observed debonding by adjusting the value of the interface bonding strength. In a final simulation, the SFLS and NFLS were taken to be $80 \mathrm{MPa}$ and $50 \mathrm{MPa}$, respectively. Debonding of composite obtained experimentally and numerically for two BF and FF configurations are shown in Figs. 8 and 9. The comparison of the experimental results and the numerical predictions, shows that the estimated data for bonding strength values are accurate enough to predict the debonding of composite layers under impact loading.

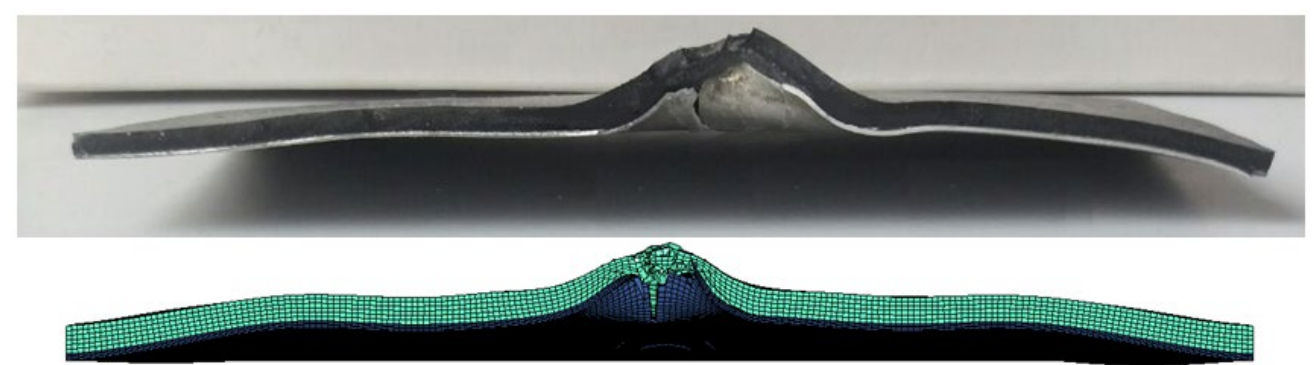

(a)

Fig. 8Comparison of (a) experimental and (b) numerical results with the rubber on the back face at the impact velocity of $144 \mathrm{~m} / \mathrm{s}$

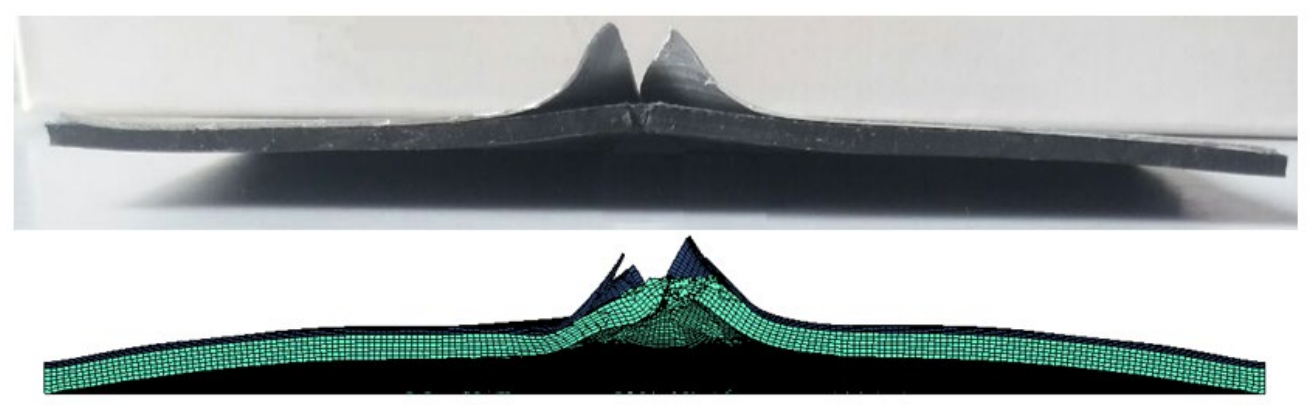


Fig. 9Comparison of (a) experimental and (b) numerical results with the rubber on the front face at the impact velocity of $144 \mathrm{~m} / \mathrm{s}$

\section{Results and discussion}

The main objective of this study is to investigate the behavior and impact resistance of aluminum-rubber composite plate. The effect of rubber layer on energy absorptionand failure mechanism of the composite plate has been studied.To carry on the study a series of experimental tests and numerical analysis were performed onsingle layer aluminum plate and bilayer aluminum-rubber samples.

\subsection{Impact on aluminum plate}

To evaluate the impact resistance of aluminum plate, impact tests were conducted using gas gun at five different gas reservoir pressure of 6,9,12,15 and 18 bar. These pressurelaunched the projectile with the velocities of $75,96,109,122$ and $129 \mathrm{~m} / \mathrm{s}$ respectively. These values were chosen to be greater than ballistic limit.The hemispherical projectile impacted the 0.5 $\mathrm{mm}$ aluminum plateand residual velocity, global deformation and the fracture mechanisms wereevaluated. The scare of the impact on the plateat penetration zone, had 4 petals. By increasing the impact velocity, the larger petals were shownat penetration zone.

A numerical simulation was performed to investigate the aluminum plate behavior under impact loading. This was done in parallel with the experiment to validate theenergy absorptionof the target plate at velocities which experiments were performed. The failure mode also was compared with the experiments. Fig. 10 shows the perforated aluminum plate at incidence velocity of $109 \mathrm{~m} / \mathrm{s}$. Four petals formed at this velocity have been compared experimentally and numerically in Fig. 10a-b. The compared results show, the predicted numerical model is in close agreement with the experiment. Plate was deformed under impact 
of projectile and when the stress is beyond the tensile strength of material, cracks appear in vicinity of the impact zone. Cracks will be propagated until the projectile perforates the plate. The perforation process isshown in Fig. 11.
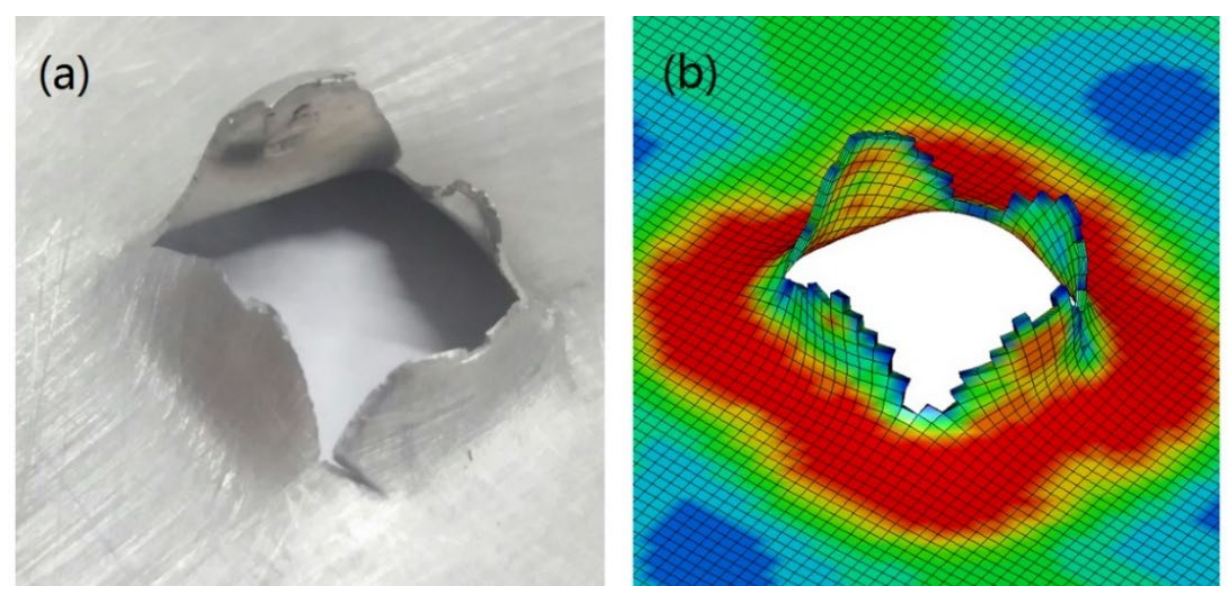

Fig. 10Comparison of (a) experimental and (b) numerical results at initial velocity of $109 \mathrm{~m} / \mathrm{s}$.

The projectile's residual velocity versus impact initial velocity of the aluminum plate is shown in Fig. 12. The residual velocities from the simulations show good agreement with the experimental test results. To determine the ballistic limit velocity, simulation was carried out considering different velocities. The aim was to find a velocity in which the residual velocity becomes zero when the projectile was completely perforated into the specimen. The ballistic limit velocity of monolithic aluminum plate was found to be $50.5 \mathrm{~m} / \mathrm{s}$.
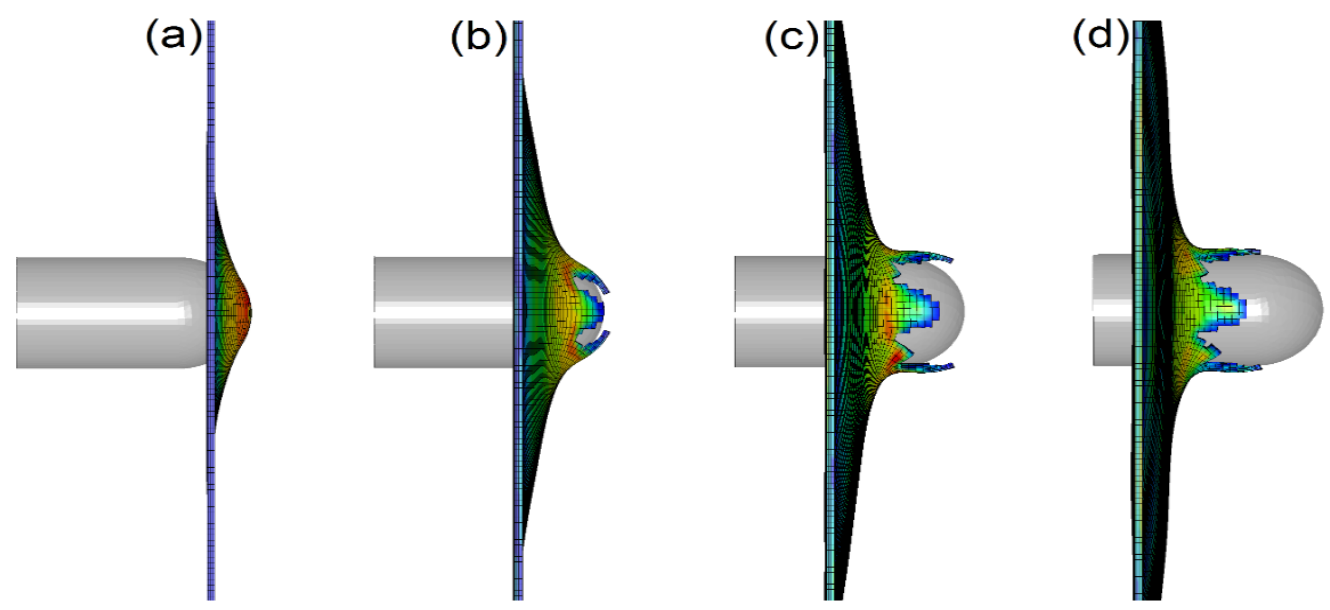
Fig. 11Perforation of projectile at initial velocity of $129 \mathrm{~m} / \mathrm{s}$ at (a) 30 (b) 60 (c) 90 and (d) $120 \mu$ s time interval.

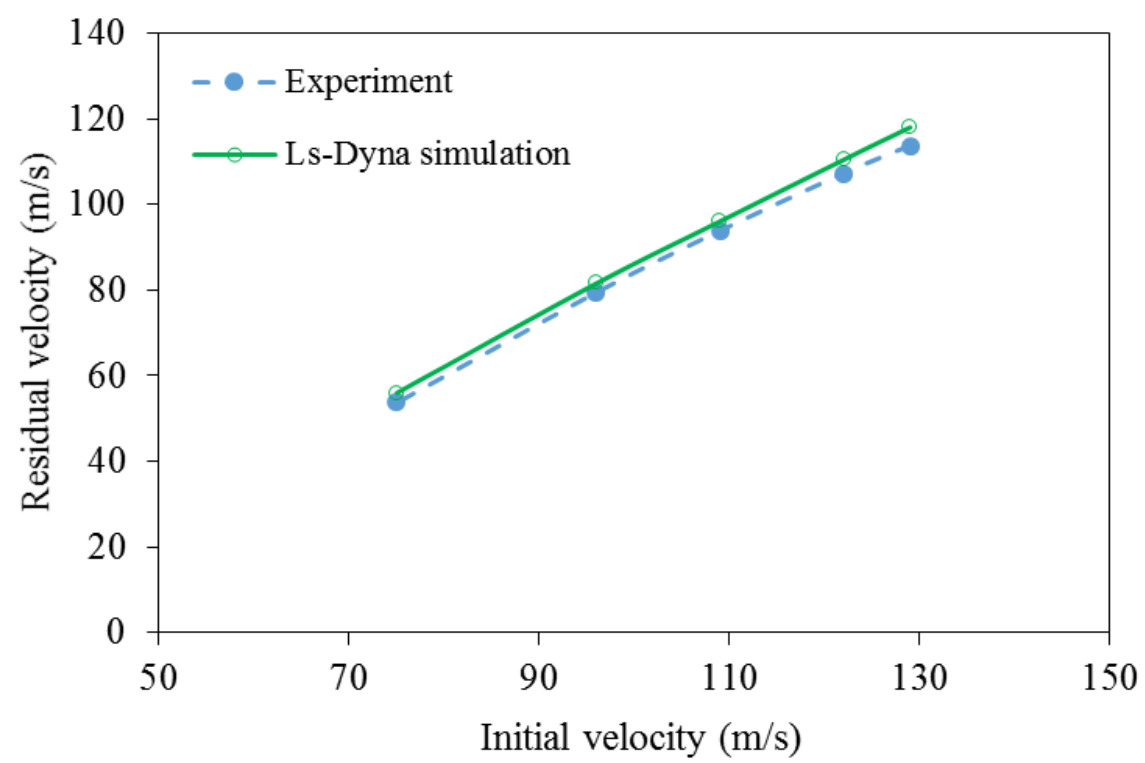

Fig. 12 Experimental and numerical comparison of residual velocity versus impact velocity after perforating the aluminum plate

\subsection{Impact on aluminum-rubber plate}

The aluminum-rubber bilayer samples were setup using two different configurations: first the rubber located on the impact face (front face; FF) and second the rubber layer located on the face opposite to the impact side (back face; BF). Tests were conducted at fourdifferent velocity groups of $75 \mathrm{~m} / \mathrm{s}, 101 \mathrm{~m} / \mathrm{s}, 144 \mathrm{~m} / \mathrm{s}$ and $168 \mathrm{~m} / \mathrm{s}$. Each test repeated five timesand average velocity was calculated for each test group.

The experimental and numerical behavior of the aluminum-rubber composite when rubber layer located on the back face (BF)are presented in Figs. 13-15 under the impact velocities of $75 \mathrm{~m} / \mathrm{s}, 144 \mathrm{~m} / \mathrm{s}$ and $168 \mathrm{~m} / \mathrm{s}$, respectively.A good agreement is shown between numerical and experimental results. The damage occurred in case of $75 \mathrm{~m} / \mathrm{s}$ which is lower than ballistic limit velocity is shown in Fig. 13. In this case, Aluminum layer was damaged and projectile penetrated the aluminum layer, but rubber panel resisted against projectile impact. Also 
projectile rotation was observed when impact velocity is lower than ballistic limit velocity. In impact velocities higher than ballistic limit (Figs. 14 and 15), projectile perforated the bilayer composite and passed the target without rotation.

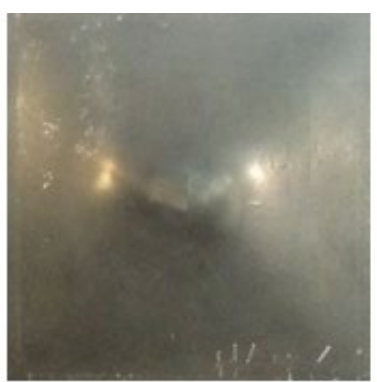

(a)

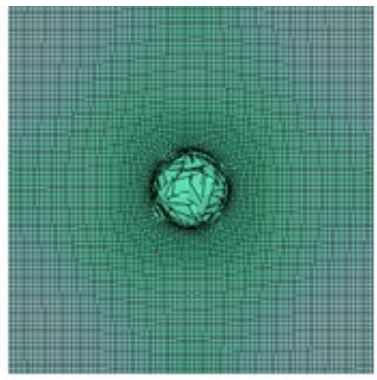

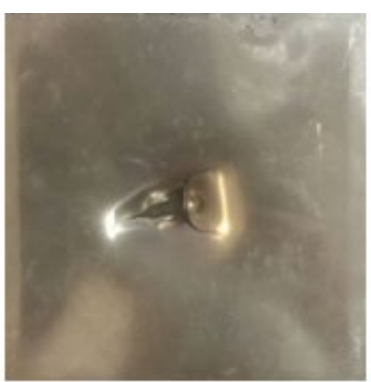

(b)

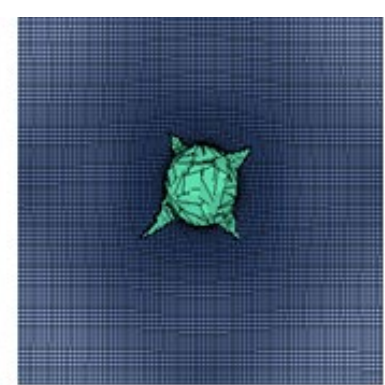

Fig. 13 Failure of composite with the rubber on the back face at the impact velocity of $75 \mathrm{~m} / \mathrm{s}$ obtained Experimentally and numerically (a) Back view (b) Front view
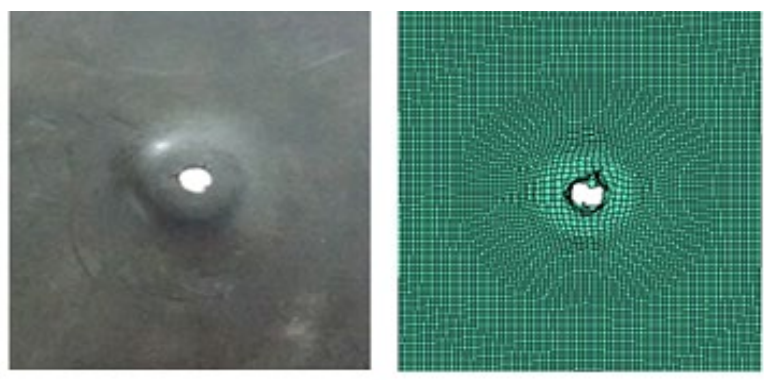

(a)

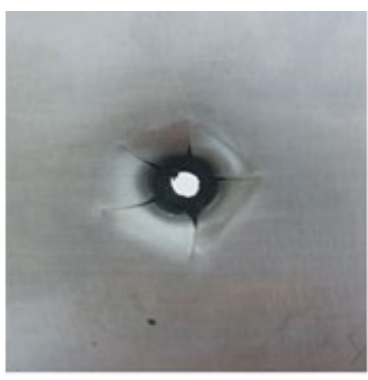

(b)

Fig. 14 Failure of composite with the rubber on the back face at the impact velocity of $144 \mathrm{~m} / \mathrm{s}$ obtained Experimentally and numerically (a) Back view (b) Front view
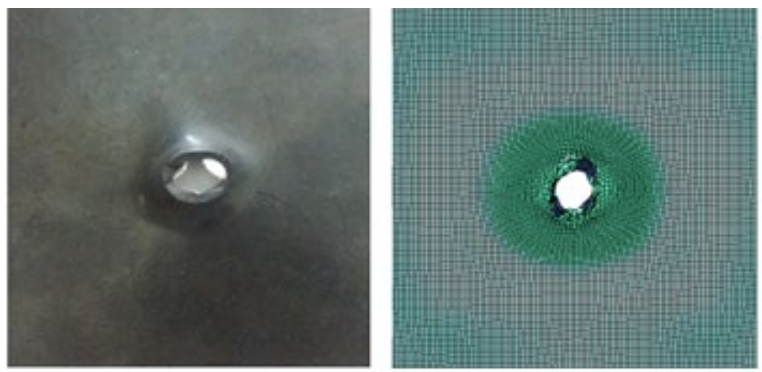

(a)

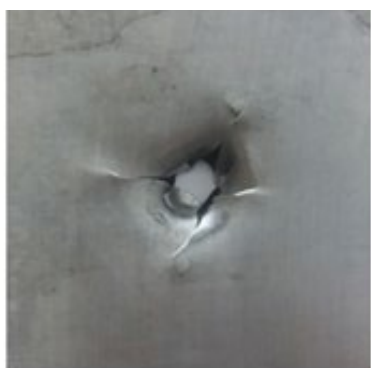

(b)

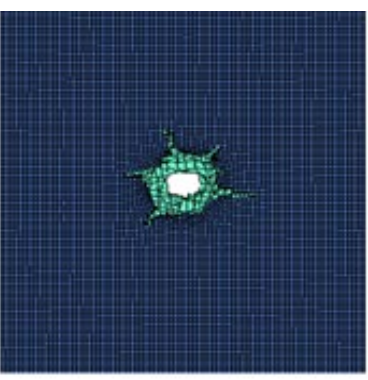


Response of the composite plate when the rubber layer is located on the front face (FF) under the similar impact velocities are shown in Figs. 16-18.It is shown that in this configuration, model predictions are in good agreement with experimental results. The response of bilayer composite when projectile velocity is lower than ballistic limit velocity is shown in Fig. 16. In this case, aluminum layer was deformed but no damage and fracture was observed in composite. Similar to BF configuration, projectile rotation was observed when impact velocity is lower than ballistic limit velocity. In impact velocities higher than ballistic limit (Figs. 17 and 18), projectile perforated the bilayer composite and passed the target without rotation.
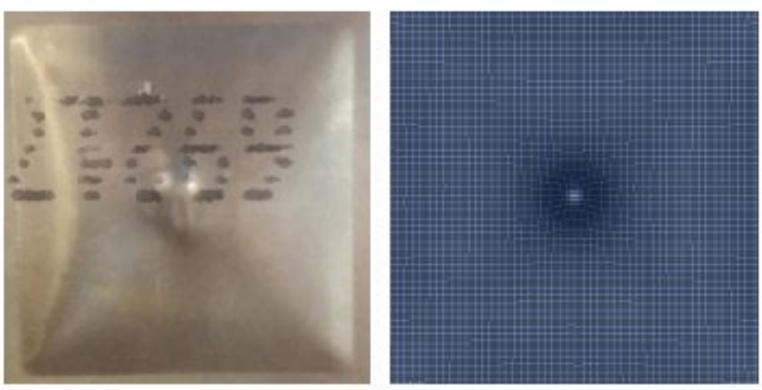

(a)
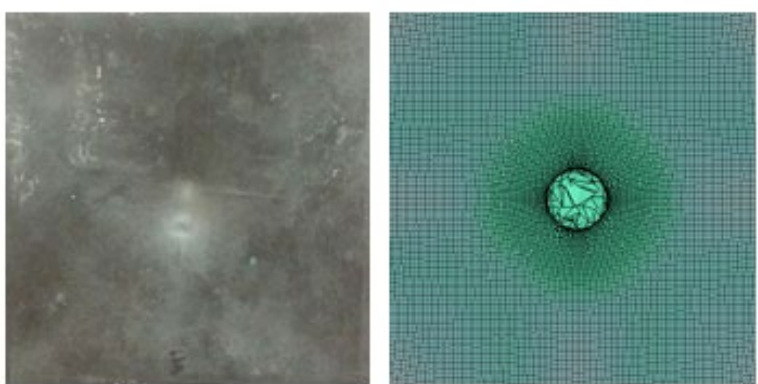

(b)

Fig. 16 Failure of composite with the rubber on the front face at the impact velocity of $75 \mathrm{~m} / \mathrm{s}$ obtained Experimentally and numerically (a) Back view (b) Front view

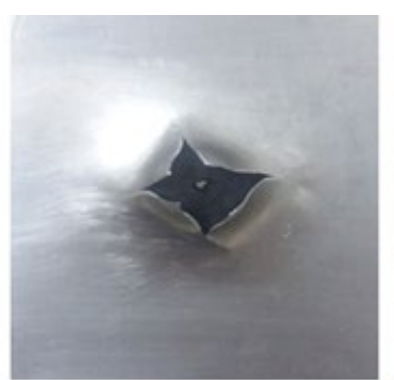

(a)

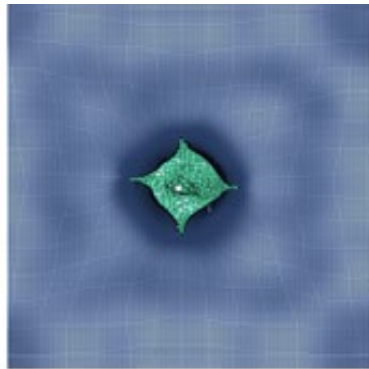

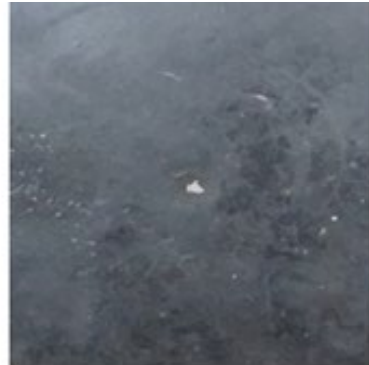

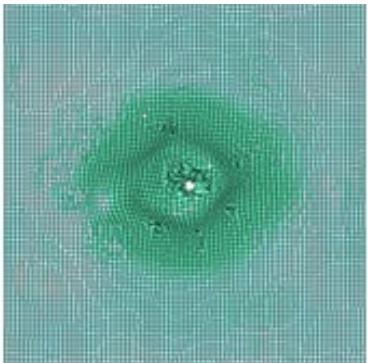

(b)

Fig. 17 Failure of composite with the rubber on the front face at the impact velocity of $144 \mathrm{~m} / \mathrm{s}$ obtained Experimentally and numerically (a) Back view (b) Front view 


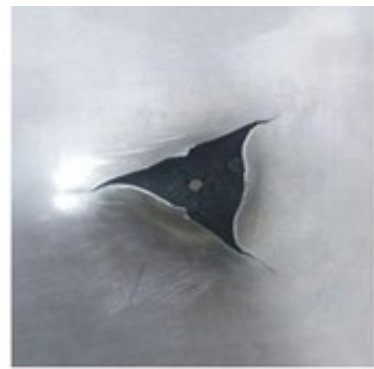

(a)

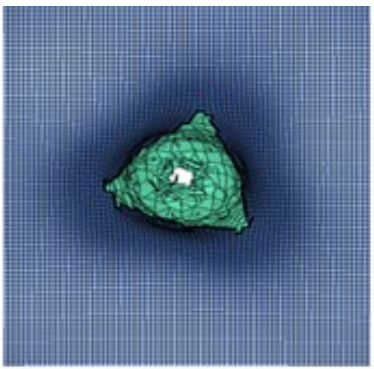

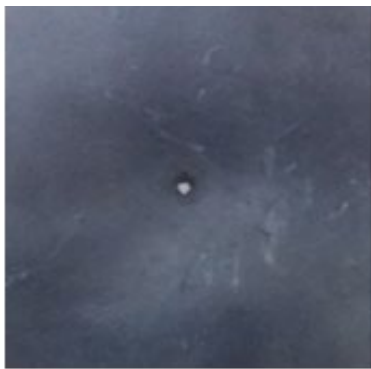

(b)

Fig. 18 Failure of composite with the rubber on the front face at the impact velocity of $168 \mathrm{~m} / \mathrm{s}$ obtained Experimentally and numerically (a) Back view (b) Front view

It was assumed that the loss of projectile's kinetic energy is equal to the energy absorption performed by the composite target in at the perforation event. Therefore the energy absorption of the composite target can be theoretically calculated by subtracting the residual energy of the projectile from its initial energy as presented below.

$$
E_{P}=\frac{1}{2} m_{p}\left(V_{i}^{2}-V_{r}^{2}\right)
$$

Where $E_{p}(J)$ is dissipated energy during the impact process, $m_{p}(\mathrm{~kg})$ is mass of the projectile, $\mathrm{V}_{\mathrm{i}}(\mathrm{m} / \mathrm{s})$ is projectile initial velocity, and $\mathrm{V}_{\mathrm{r}}(\mathrm{m} / \mathrm{s})$ is residual velocity. Table 4 presents the experimental and numerical results performed for BF and FF configurations.In this table,the experimental test results, which were performed at velocities of 75,101, 144 and $168 \mathrm{~m} / \mathrm{s}$, are presented. A high hardness rubber layer was used for experimental tests. The residual velocity of the projectile was measured and the energy absorption is determined using Equation (6). Energy absorption is used as criteriato evaluate the ballistic performance of the composite plate. Table 4 indicates that the numerical model can be used to estimate the projectile residual velocity and energy absorbed by bilayer composite. 
Table 4 Comparison of energy absorption obtained by experimental and numerical simulation

\begin{tabular}{ccccccc}
\hline Configuration & $\begin{array}{c}\text { Impact } \\
\text { velocity } \\
(\mathrm{m} / \mathrm{s})\end{array}$ & $\begin{array}{c}\text { Experimental } \\
\text { residual } \\
\text { velocity }(\mathrm{m} / \mathrm{s})\end{array}$ & $\begin{array}{c}\text { Numerical } \\
\text { residual } \\
\text { velocity }(\mathrm{m} / \mathrm{s})\end{array}$ & $\begin{array}{c}\text { Experimental } \\
\text { energy } \\
\text { absorption }(\mathrm{J})\end{array}$ & $\begin{array}{c}\text { Numerical } \\
\text { energy } \\
\text { absorption }(\mathrm{J})\end{array}$ & $\begin{array}{c}\text { Error } \\
(\%)\end{array}$ \\
\hline \multirow{3}{*}{ Rubber in } & 75 & 0 & 0 & 26.2 & 26.2 & 0 \\
back face & 101 & 58.4 & 64.5 & 31.6 & 28.1 & 11.1 \\
& 144 & 114.6 & 117.2 & 35.4 & 32.6 & 7.9 \\
& 168 & 138.7 & 141.5 & 41.9 & 38.2 & 8.8 \\
\hline \multirow{2}{*}{ Rubber in } & 75 & 0 & 0 & 26.2 & 26.2 & 0 \\
front face & 101 & 44.8 & 53.6 & 38.2 & 34.1 & 10.7 \\
& 144 & 104.5 & 107 & 45.7 & 43.3 & 5.2 \\
& 168 & 133.9 & 137.6 & 48 & 43.3 & 9.8 \\
\hline
\end{tabular}

\section{Parametric study}

A parametric study on bilayer aluminum-rubber composite plate under impact loading was performed. The main parameters that were investigated are: the relative position of the rubber layer with respect to the loading direction, the effect of different impact velocities, the effect of rubber hardness, the effect of rubber layer thickness, the strength of rubber-aluminum bonding and ballistic performance of aluminum-rubber sandwich panel. The residual velocity of projectile was measured in simulations and the energy absorption of bilayer composite was calculated and considered as a criterion to compare their impact resistance. The projectile used in the finite element models reported in this section has a mass of $9.32 \mathrm{~g}$ for all the modeled samples. Also, all the aluminum plate models have thickness of $0.5 \mathrm{~mm}$.

\subsection{Effect of relative position}

As it is mentioned in the previous section, to study the effect of the relative position of rubber, two configurations of bilayer composite plate were considered. First configuration, the rubber layer was located on the impact receiving side, front face (FF), and second, the rubber panel 
was located on the back face of impact $(\mathrm{BF})$. In this section numerical simulation was performed in different impact velocities to see the effect of rubber layer position. Also, the ballistic limit of the compositetarget was determined. The high hardness $(\mathrm{HH})$ rubber layer was used and the interface shear and normal bonding strength was assumed to be 80 and 50 $\mathrm{MPa}$, respectively. Rubber layer with thicknessof $2 \mathrm{~mm}$ and aluminum layer with thickness of $0.5 \mathrm{~mm}$ were used to investigate the effect of relative position. Figure 19 shows the residual velocity of projectile after perforating the bilayer composite versus impact velocity for two BF and FF configurations.Moderate enhancement in ballistic performance in terms of lower residual velocity for bilayer composite plate, which rubber layer located in front face, was observed and compared to the corresponding back face configuration. It was find out that the compositeplate by front face rubber layer configuration shows a better penetration resistance compared to the back face composite plate.

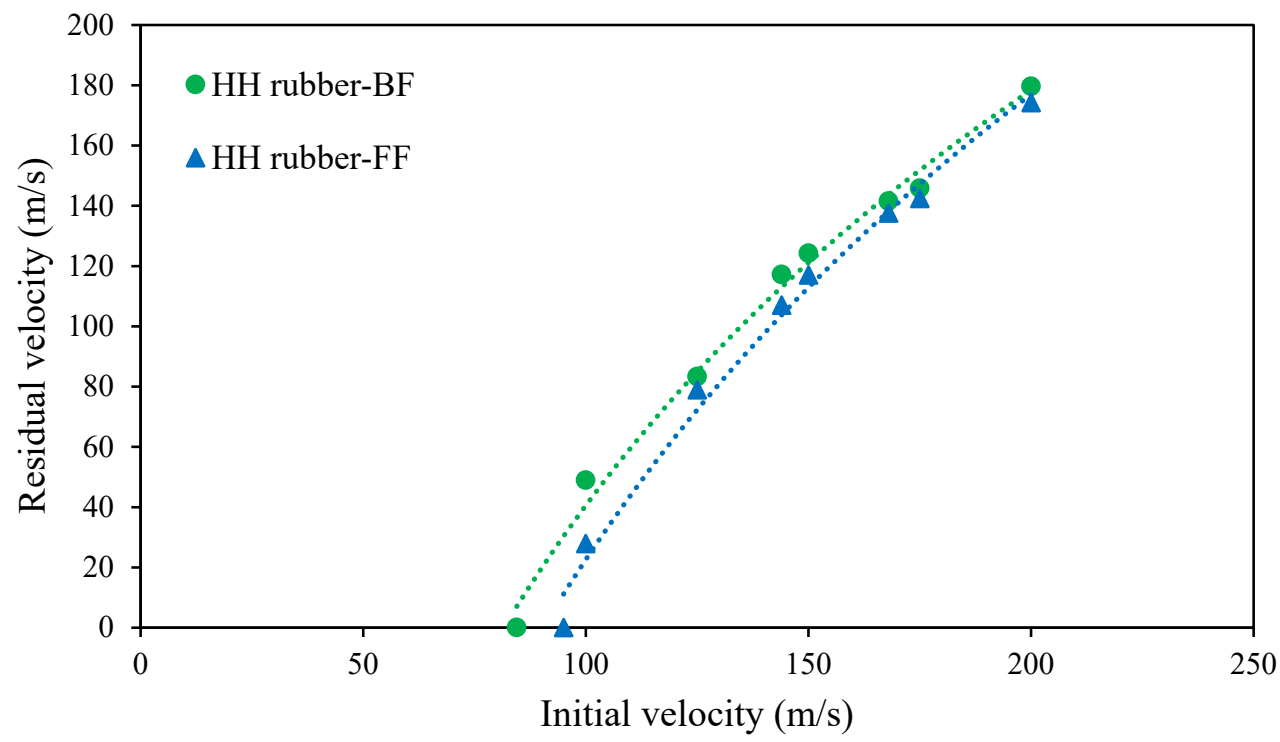

Fig. 19Residual velocities versus initial velocities of Al-HH rubber composite for BF and FF configuration 
The ballistic limits obtained by numerical analysis for the composite plate with BF and FF configurations are 84.5 and $95 \mathrm{~m} / \mathrm{s}$, respectively. While, in Section 4.1, it was observed that the ballistic limit for the single-layer aluminum plate is $50.5 \mathrm{~m} / \mathrm{s}$. Comparing the ballistic limit of the bilayer aluminum-rubber composite with the ballistic limit of the aluminum plate shows the rubber layer with high damping properties has a significant effect on the energy absorption of the composite target. Increase in the ballistic limit of composite with the BF and FF configurations is $67.3 \%$ and $88.1 \%$, respectively.

\subsection{Effect of rubber hardness}

It is known that in rubber material the formulation of its component has influence on its mechanical properties and its impact resistance properties. In this section the numerical simulation was performed onthe bilayer aluminum-low hardness rubber (LH) composite plate and compared to the composite plate made by $\mathrm{HH}$ rubber. Rubber layer with thickness of 2 $\mathrm{mm}$ for both $\mathrm{LH}$ and $\mathrm{HH}$ rubber and aluminum layer with thickness of $0.5 \mathrm{~mm}$ were used to investigate the effect of rubber hardness. Figs. 20 and 21 show the residual velocity of projectile versus initial velocity after perforation of two types composite with $\mathrm{HH}$ and LH rubber layer for $\mathrm{BF}$ and $\mathrm{FF}$ configuration. The figures show higher ballistic performance in term of lower residual velocity for the composite plate made by $\mathrm{HH}$ rubber compared to corresponding LH rubber composite plate. This advantage is applicable for both BF and FF configurations. The higher energy absorption capacity of HHrubber compare to LHrubber can be referred to its stronger molecular chains. 


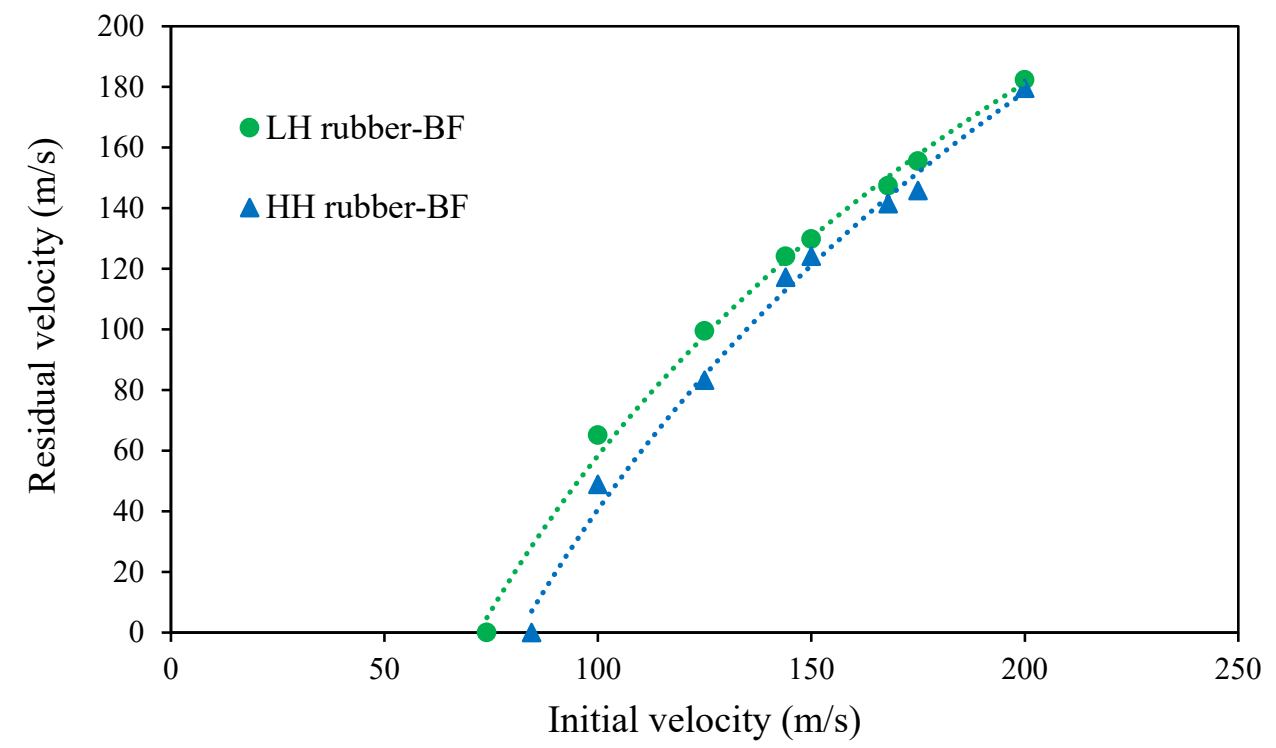

Fig.20Residual velocities versus initial velocities of Al-rubber composite with LH and HH rubber layer for BF configuration

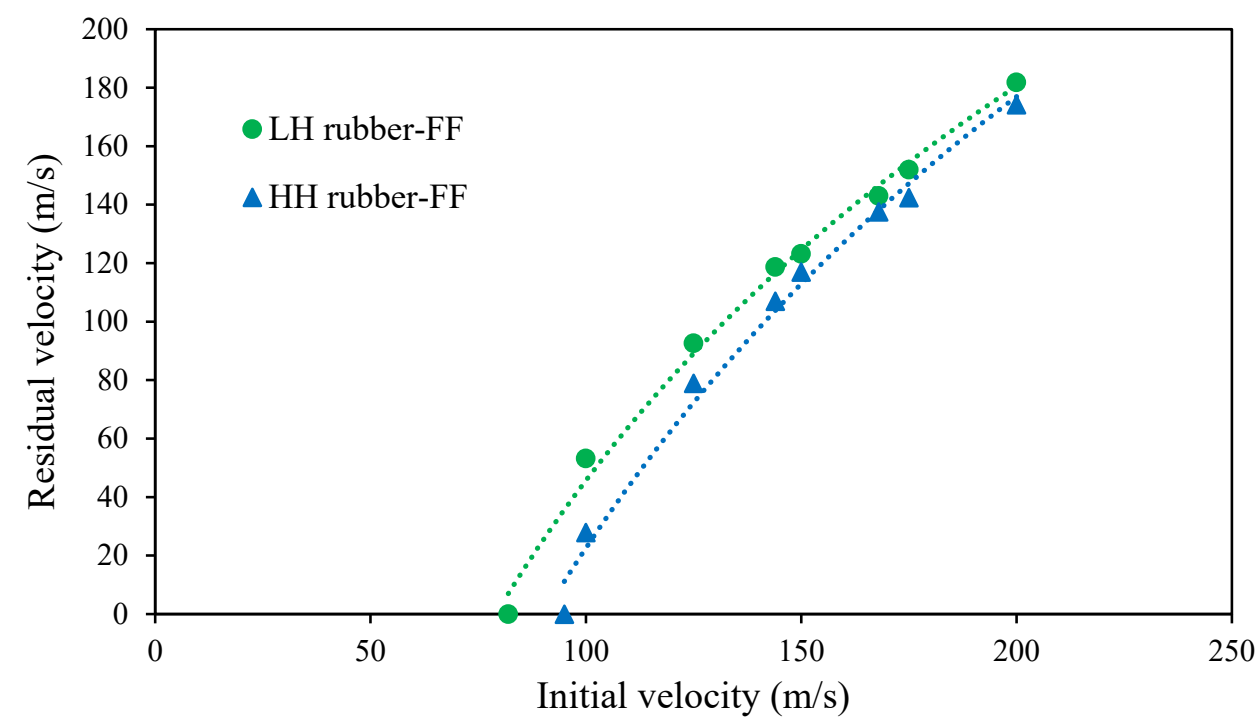

Fig.21Residual velocities versus initial velocities of Al-rubber composite with LH and HH rubber layer for FF configuration

Fig. 22illustrates the projectile velocity histories at impact velocity of $150 \mathrm{~m} / \mathrm{s}$ on the bilayer composites plate made by $\mathrm{LH}$ and $\mathrm{HH}$ rubber layers for $\mathrm{BF}$ and $\mathrm{FF}$ configurations. As it is shown in the figure, the specimens'perforation and the residual velocities are different. From observations of Figure22, following points are notable: 
(i) The velocity deceleration rate of the projectile impacting the compositetarget with $\mathrm{HH}$ rubber is higher than the LHcase, which means the deceleration rate of the composite sample is directly related to the hardness of the rubber.

(ii) The residual velocity of the projectile impacting the aluminum-HH rubber layeris lower than the aluminum-LH rubber composite sample.

(iii) The first level of composite behavior with $\mathrm{BF}$ configuration is affected by the aluminum performance causing the intense deceleration of the projectile velocity. After failure of the aluminum plate, the gradient is gentle due to low module and large elongation to failure of the rubber.

(iv) Time duration of penetration is longer for the composites targets with FF configuration compared with the composites targets with BF configuration.

(v) The residual velocity of the projectile impacting on the composite plate with FF configuration is lower compared to BF configuration.

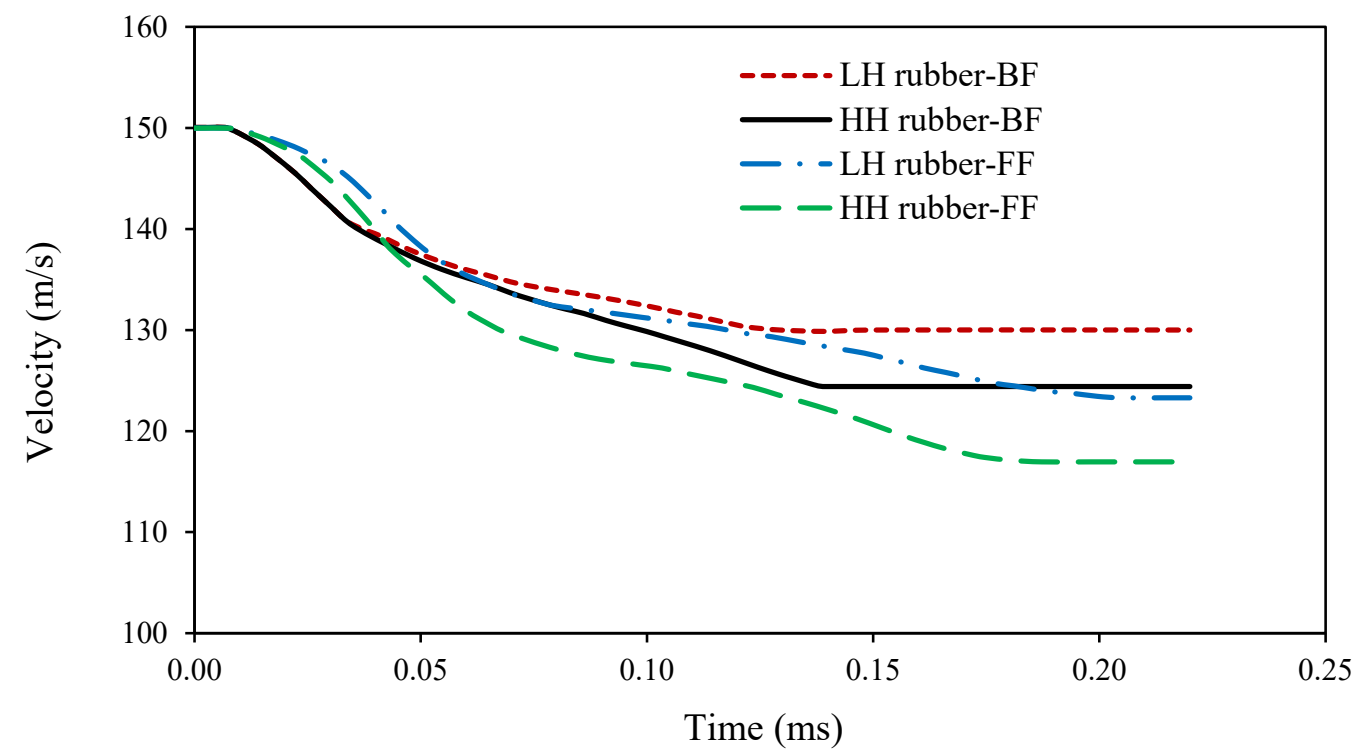

Fig.22Comparison of projectile velocity histories at impact velocity of $150 \mathrm{~m} / \mathrm{s}$ on LH and HH Alrubber composite for $\mathrm{BF}$ and $\mathrm{FF}$ configuration 


\subsection{Effect of rubber layer thickness}

A set of simulations was performed to study the effect of the rubber layer thickness on the performance of the bilayer Al-rubber composite target. In these simulations the thickness of aluminum layer was $0.5 \mathrm{~mm}$ and the thicknesses of the rubber layer were $0.5 \mathrm{~mm}, 1 \mathrm{~mm}, 1.5$ $\mathrm{mm}, 2 \mathrm{~mm}, 2.5 \mathrm{~mm}$, and $3 \mathrm{~mm}$, as shown in Table 5. The simulations were performed for both $\mathrm{BF}$ and FF configurations. The HH rubber layer was used and the interface shear stress and normal stress at bonding interface was assumed to be $80 \mathrm{MPa}$ and $50 \mathrm{MPa}$, respectively.

Fig. 23 compares the energy absorption of each composite platewith different rubber layer thickness. The comparison reveals that the increase in the thickness of the rubber layer improves the overall performance of the bilayer plates for both $\mathrm{BF}$ and FF configuration. In the case of FF configuration the rubber thickness is more effective, in which increasing the rubber layer thickness, significantly increase the energy absorption of the composite target.

Table 5 Numerical modeling of Al-rubber composite with different rubber thickness

\begin{tabular}{ccc}
\hline $\begin{array}{c}\text { Al thickness } \\
(\mathrm{mm})\end{array}$ & $\begin{array}{c}\text { Rubber thickness } \\
(\mathrm{mm})\end{array}$ & Al-rubber composite \\
\hline & 0.5 & \\
& 1 & \\
0.5 & 1.5 & \\
& 2 & \\
& 2.5 & \\
& 3 & \\
\hline
\end{tabular}




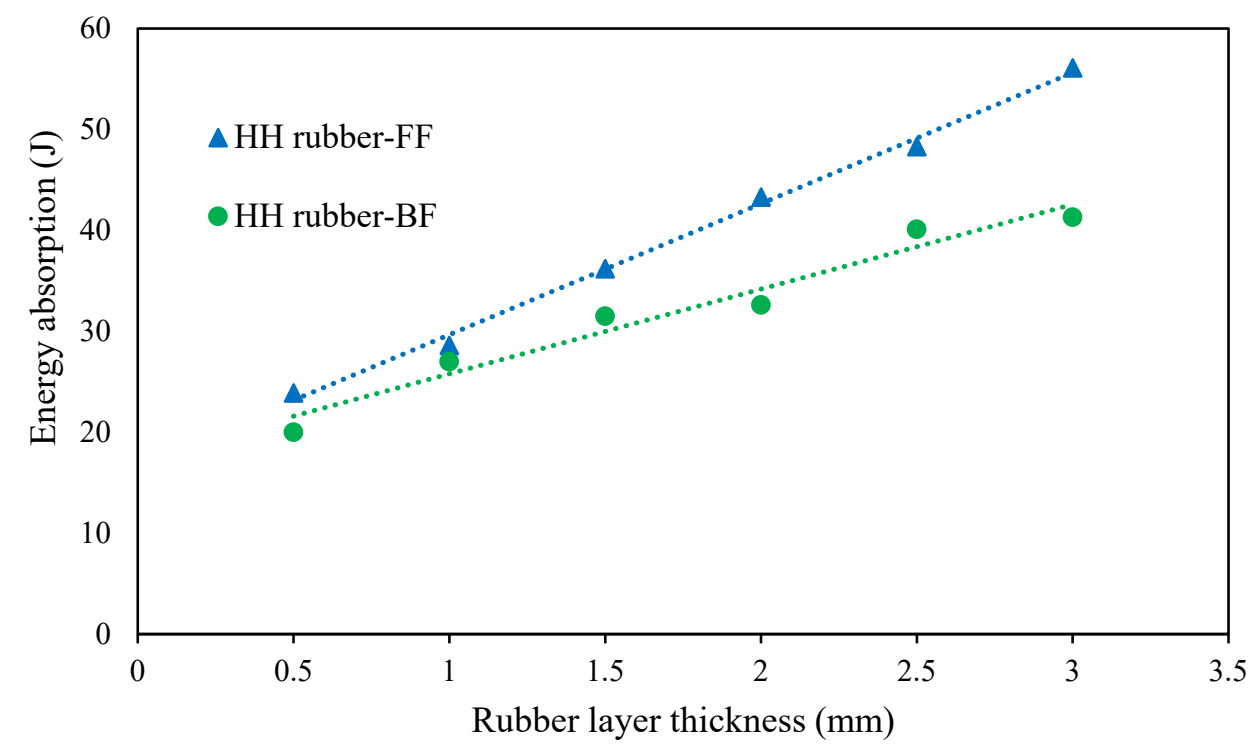

Fig.23Energy absorption of Al-HH rubber composite with different rubber layer thickness for BF and FF configuration

\subsection{Effect of bonding}

A simulation was performed to evaluate the effect of the aluminum-rubber interface bonding strength on the performance of the bilayer composite plate. The thicknesses of aluminum and rubber layer were $0.5 \mathrm{~mm}$ and $2 \mathrm{~mm}$, respectively and $\mathrm{HH}$ rubber was used in these simulations. The initial velocity of projectile was set to be $144 \mathrm{~m} / \mathrm{s}$ for each simulation. For all simulation residual velocity was measured and the energy absorption was calculated. The values of the bonding strength used for these simulations are from the low to high bonding values. Six values of interface bonding strength were considered in this study and simulation was performed to evaluate the ballistic performance of each configuration and bonding interface. The bonding values between rubber and aluminum layer were considered to be $0-0$ (which means two layers does not have any bonding and are separated with each other), 20S$12 \mathrm{~N}, 40 \mathrm{~S}-25 \mathrm{~N}, 60 \mathrm{~S}-38 \mathrm{~N}, 80 \mathrm{~S}-50 \mathrm{~N}$, and Tie (perfect bonding). Fig. 24 shows the energy 
absorption capacity of the bilayer composite plate with BF and FF configurationswith different interface bonding strength. It can be seen that increase bonding has negative effect on ballistic performance of composite for both $\mathrm{BF}$ and FF configurations. This parameter specially affects the $\mathrm{BF}$ configuration. It is shown that in $\mathrm{BF}$ configuration when there is no bonding, rubber plate can stretch without any limitation and have the best performance. By increasing the interface bonding between the rubber and aluminum plate, the energy absorption of bilayer composite decreases. It can be seen that there is a critical interface bonding point which BF and $\mathrm{FF}$ configurations has same performance. BF configuration has the better performance for interface bonding values less than critical point. On the other hand, by increasing the bonding beyond the critical point, the FF configuration has better performance.

Figs. 25 and 26 show the deformation of bilayer composite for BF and FF configuration, respectively. It can be seen that bonding restricts the rubber deformation and doesn't let the rubber layer to present its stretch and damping properties.

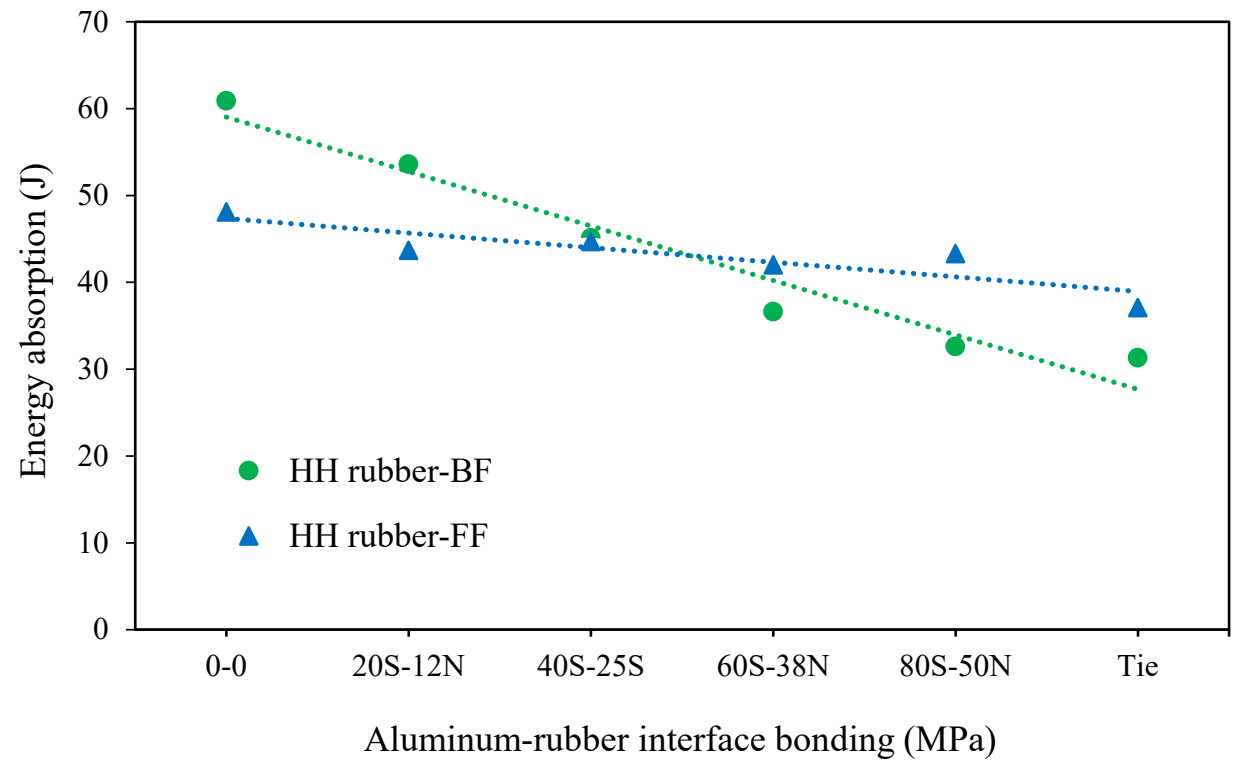

Fig.24Energy absorption of Al-HH rubber composite with different interface bonding for BF and FF configuration 


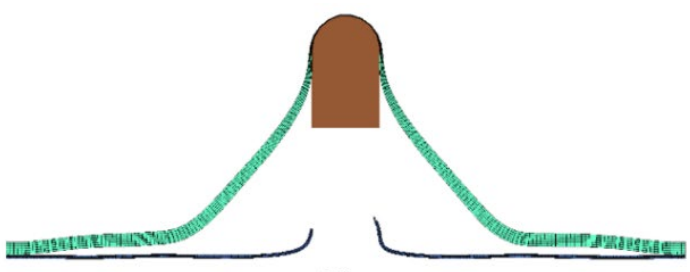

(a)

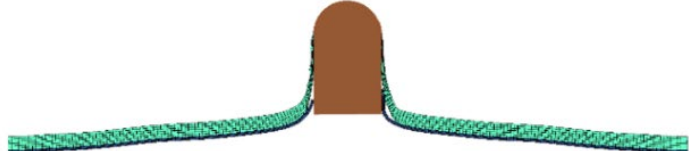

(c)

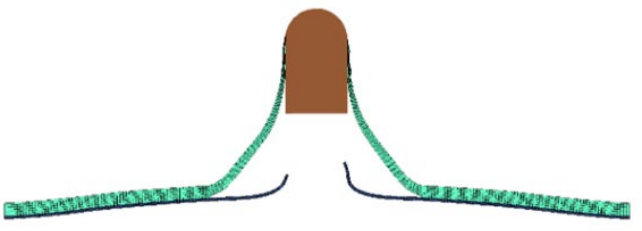

(b)

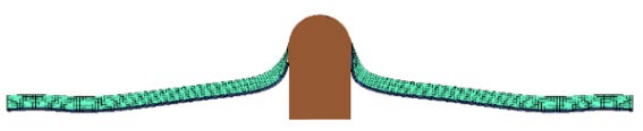

(d)

Fig.25 Impact behavior of Al-rubber composite at initial velocity of $144 \mathrm{~m} / \mathrm{s}$ for BF configuration with interface boning of (a) 0-0 (b) 20S-12N (c) $80 \mathrm{~S}-50 \mathrm{~N}$ (d) Tie

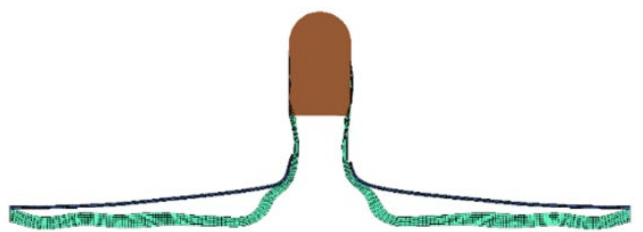

(a)

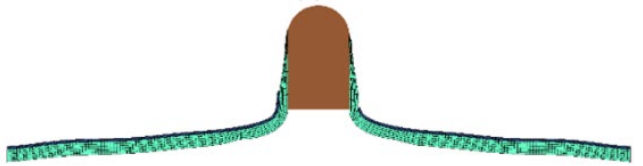

(c)

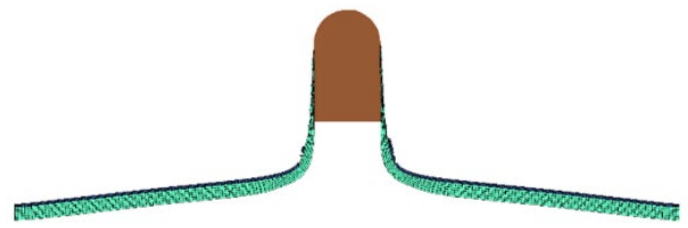

(b)

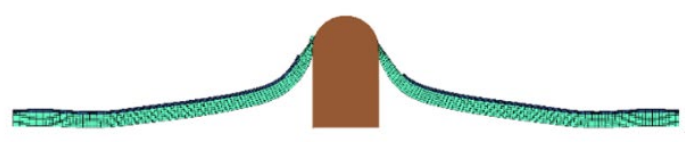

(d)

Fig.26 Impact behavior of Al-rubber composite at initial velocity of $144 \mathrm{~m} / \mathrm{s}$ for FF configuration with interface boning of (a) $0-0$ (b) $20 \mathrm{~S}-12 \mathrm{~N}$ (c) $80 \mathrm{~S}-50 \mathrm{~N}$ (d) Tie

\subsection{Aluminum-rubber sandwich panel}

A simulation was performed to evaluate the response of an aluminum-rubber sandwich panel under impact loading. For this purpose, a $0.5 \mathrm{~mm}$ aluminum plate was sandwiched between twolayers of $\mathrm{HH}$ rubber panel with thickness of $1 \mathrm{~mm}$ as shown in Fig. 27. The shear and normal stress at bonding interfaces were assumed to be $80 \mathrm{MPa}$ and $50 \mathrm{MPa}$, respectively. Simulations were conducted at three initial velocity of projectile which were 101, 144 and 168 $\mathrm{m} / \mathrm{s}$. The residual velocity of projectile was obtained in each simulation and compared to the results of bilayer aluminum-rubber composite which presented in Table 6 . 


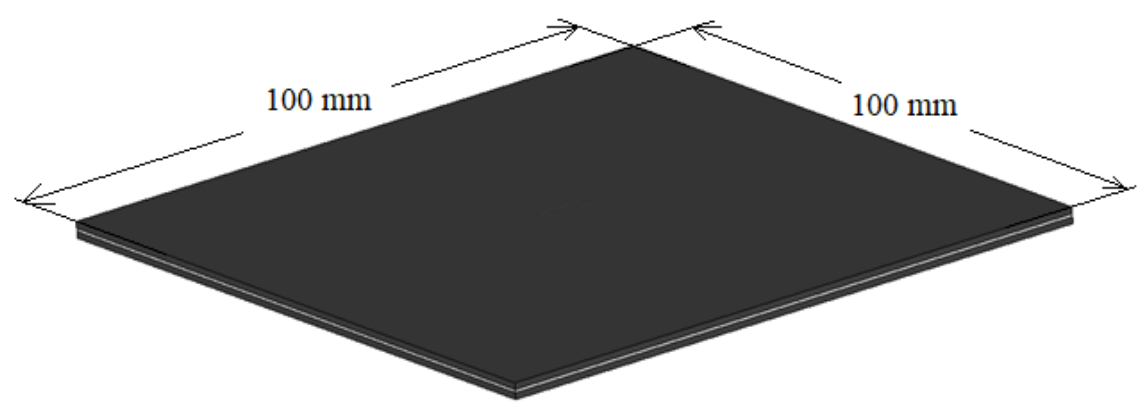

Fig. 27 Aluminum-rubber sandwich panel

It can be seen bilayer composite has better performance under impact loading compared to aluminum-rubber sandwich panel. The table shows better performance in terms of lower residual velocity for both $\mathrm{BF}$ and $\mathrm{FF}$ configuration of bilayer aluminum-rubber composite compared to aluminum-rubber sandwich panel.

Table 6 Comparison of performance of bilayer and sandwich composite

\begin{tabular}{ccccc}
\hline $\begin{array}{c}\text { Initial velocity } \\
(\mathrm{m} / \mathrm{s})\end{array}$ & Sandwich panel & 101 & 144 & 168 \\
\hline $\begin{array}{c}\text { Residual velocity } \\
(\mathrm{m} / \mathrm{s})\end{array}$ & Bilayer composite with BF configuration & 64.5 & 117.2 & 141.5 \\
& Bilayer composite with FF configuration & 53.6 & 107 & 137.6 \\
\hline
\end{tabular}

Perforated specimens under impact velocity of $144 \mathrm{~m} / \mathrm{s}$ is shown in Fig. 28. Fig. 28 (a) and (b) show the bilayer composite in FF and BF configuration, respectively andFig 28 (c) shows the sandwich panel response. Fig. 29 shows the aluminum plate used in specimens after perforation. It can be seen that by decreasing the rubber thickness on back face of aluminum plate, the larger petals are shown at penetration zone. 


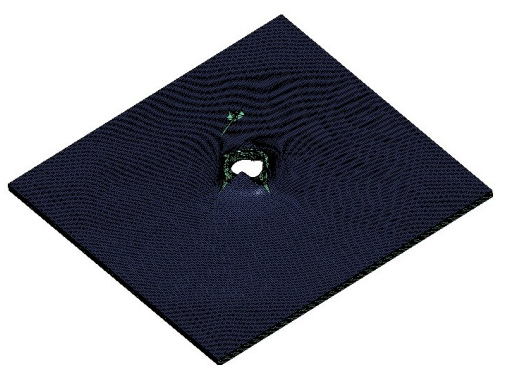

(a)

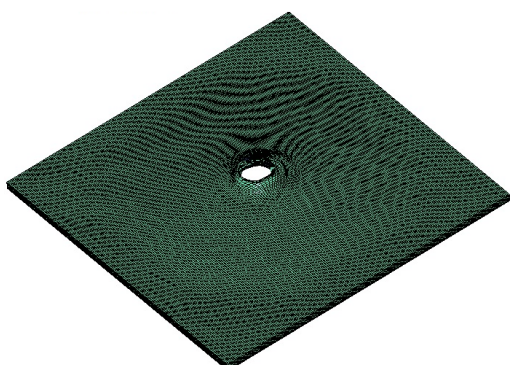

(b)

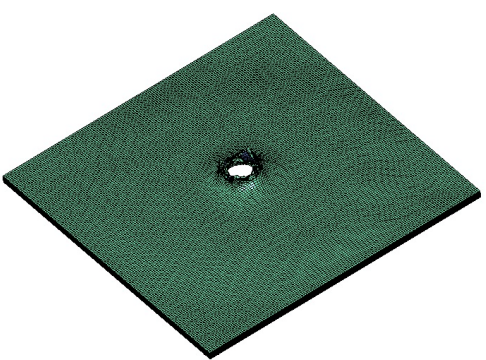

(c)

Fig. 28 Penetration of projectile in (a) Al-rubber composite with FF configuration (b) Al-rubber composite with BF configuration (c) Sandwich panel

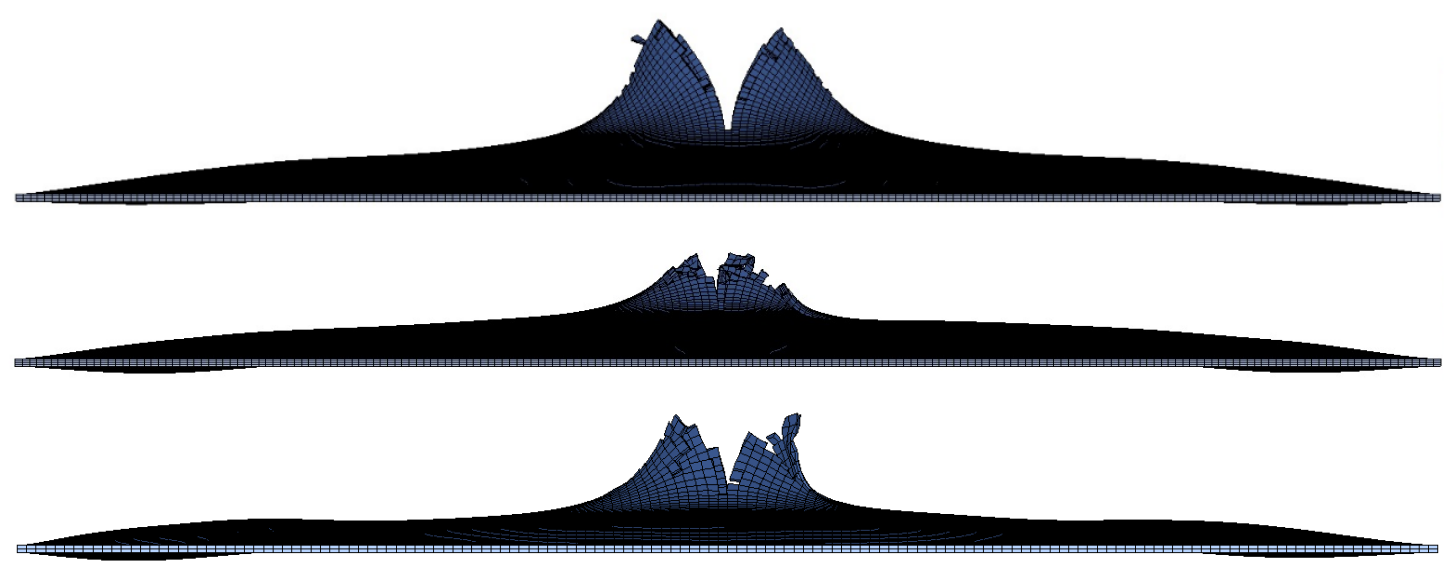

Fig. 29 Fracture of aluminum layer in (a) Al-rubber composite with FF configuration (b) Al-rubber composite with BF configuration (c) Sandwich panel

\section{Conclusion}

In this paper, mechanical behavior of an aluminum-rubber bilayer composite target plate under impact loading was investigated. A series of experimental tests were conducted using a gas gun at projectile velocities of $75 \mathrm{~m} / \mathrm{s}, 101 \mathrm{~m} / \mathrm{s}, 144 \mathrm{~m} / \mathrm{s}$ and $168 \mathrm{~m} / \mathrm{s}$. From the experiments, it was focused on the ballistic performance of composite plate considering the relative position of the rubberlayer with respect to the loading direction. It was found that when rubber layer located on the front face of bilayer aluminum-rubber composite, better ballistic performance can be 
achieved.A numerical simulation in prallel with experimental tests was developed. The simulation was suporrted using a parametric study on bilayer aluminum-rubber composite. Rubber mechanical properties, as a strain rate dependent material, were obtaind by SHPB tests and assigned to the model. A close agreement was found between numerical and experimental results.

Following conclusions can be highlightedfrom the parametric study:

1- The ballistic limits of bilayer composite with BF and FF configuration were 84.5 and 95 $\mathrm{m} / \mathrm{s}$, respectively which show $67.3 \%$ and $88.1 \%$ increase compared to the ballistic limit of the monolithic aluminum plate.

2- The ballistic performance of aluminum-rubber composite is highly dependent onto the hardness of rubber. The composite sample with higher hardness rubber can resist more efficiently against the projectile impact.

3- Increase the thickness of the rubber layer improves the overall performance of the bilayer plates for both $\mathrm{BF}$ and $\mathrm{FF}$ configurations. On the other hand, the FF configuration is more sensitive to the rubber thickness.

4- By increasing the interface bonding between the rubber and aluminum plate, the energy absorption of bilayer composite target decreases. There is a critical threshold for the interface bonding. For the case of BF configuration,the energy absorptionwould be higher if the bonding values areless than critical point. For the case of FF configuration, by increasing the bonding strength beyond the critical point, the ballistic performance would be higher. 


\section{References}

[1] G. Tiwari, M. Iqbal, P. Gupta, Energy absorption characteristics of thin aluminium plate against hemispherical nosed projectile impact, Thin-Walled Structures 126 (2018) 246-257.

[2] Z. Rosenberg, R. Kositski, E. Dekel, On the perforation of aluminum plates by 7.62 mm APM2 projectiles, International Journal of Impact Engineering 97 (2016) 79-86.

[3] M. Iqbal, S. Khan, R. Ansari, N. Gupta, Experimental and numerical studies of double-nosed projectile impact on aluminum plates, International Journal of Impact Engineering 54 (2013) 232-245.

[4] M. Rodriguez-Millan, D. Garcia-Gonzalez, A. Rusinek, F. Abed, A. Arias, Perforation mechanics of 2024 aluminium protective plates subjected to impact by different nose shapes of projectiles, Thin-Walled Structures 123 (2018) 1-10.

[5] K. Senthil, M. Iqbal, B. Arindam, R. Mittal, N. Gupta, Ballistic resistance of 2024 aluminium plates against hemispherical, sphere and blunt nose projectiles, Thin-Walled Structures 126 (2018) 94-105.

[6] K. Ackland, C. Anderson, T.D. Ngo, Deformation of polyurea-coated steel plates under localised blast loading, International Journal of Impact Engineering 51 (2013) 13-22.

[7] R. Gamache, C. Giller, G. Montella, D. Fragiadakis, C. Roland, Elastomer-metal laminate armor, Materials \& Design 111 (2016) 362-368.

[8] I. Mohagheghian, G.J. McShane, W. Stronge, Quasi-static and impact perforation of polymer-metal bi-layer plates by a blunt indenter, Thin-walled structures 117 (2017) 35-48.

[9] M. Amini, J. Simon, S. Nemat-Nasser, Numerical modeling of effect of polyurea on response of steel plates to impulsive loads in direct pressure-pulse experiments, Mechanics of Materials 42(6) (2010) 615-627.

[10] M. Amini, J. Isaacs, S. Nemat-Nasser, Investigation of effect of polyurea on response of steel plates to impulsive loads in direct pressure-pulse experiments, Mechanics of Materials 42(6) (2010) 628-639.

[11] C. Roland, D. Fragiadakis, R. Gamache, Elastomer-steel laminate armor, Composite structures 92(5) (2010) 1059-1064.

[12] C. Roland, D. Fragiadakis, R. Gamache, R. Casalini, Factors influencing the ballistic impact resistance of elastomer-coated metal substrates, Philosophical Magazine 93(5) (2013) 468-477.

[13] M. Grujicic, B. Pandurangan, T. He, B. Cheeseman, C.-F. Yen, C. Randow, Computational investigation of impact energy absorption capability of polyurea coatings via deformation-induced glass transition, Materials Science and Engineering: A 527(29-30) (2010) 7741-7751.

[14] H. Yang, X.-F. Yao, S. Wang, Y.-C. Ke, S.-H. Huang, Y.-H. Liu, Analysis and Inversion of Contact Stress for the Finite Thickness Neo-Hookean Layer, Journal of Applied Mechanics 85(10) (2018) 101008.

[15] A. Khodadadi, G. Liaghat, A.R. Bahramian, H. Ahmadi, Y. Anani, S. Asemani, O. Razmkhah, High velocity impact behavior of Kevlar/rubber and Kevlar/epoxy composites: A comparative study, Composite Structures 216 (2019) 159-167.

[16] H. Pouriayevali, Y. Guo, V. Shim, A visco-hyperelastic constitutive description of elastomer behaviour at high strain rates, Procedia Engineering 10 (2011) 2274-2279.

[17] H. Yang, X. Yao, Z. Zheng, L. Gong, L. Yuan, Y. Yuan, Y. Liu, Highly sensitive and stretchable graphenesilicone rubber composites for strain sensing, Composites Science and Technology 167 (2018) 371-378.

[18] N. Hassim, M.R. Ahmad, W.Y.W. Ahmad, A. Samsuri, M.H.M. Yahya, Puncture resistance of natural rubber latex unidirectional coated fabrics, Journal of Industrial Textiles 42(2) (2012) 118-131.

[19] Y. Dong, Y. Ke, Z. Zheng, H. Yang, X. Yao, Effect of stress relaxation on sealing performance of the fabric rubber seal, Composites Science and Technology 151 (2017) 291-301. 
[20] H. Yang, X.-F. Yao, Y.-C. Ke, Y.-j. Ma, Y.-H. Liu, Constitutive behaviors and mechanical characterizations of fabric reinforced rubber composites, Composite Structures 152 (2016) 117-123.

[21] H. Yang, X.-F. Yao, H. Yan, Y.-n. Yuan, Y.-F. Dong, Y.-H. Liu, Anisotropic hyper-viscoelastic behaviors of fabric reinforced rubber composites, Composite Structures 187 (2018) 116-121.

[22] A. Khodadadi, G. Liaghat, H. Ahmadi, A.R. Bahramian, O. Razmkhah, Impact response of Kevlar/rubber composite, Composites Science and Technology 184 (2019) 107880.

[23] M. Bhattacharya, A.K. Bhowmick, Synergy in carbon black-filled natural rubber nanocomposites. Part I: Mechanical, dynamic mechanical properties, and morphology, Journal of materials science 45(22) (2010) 6126-6138.

[24] H.H. Cai, S.D. Li, G.R. Tian, H.B. Wang, J.H. Wang, Reinforcement of natural rubber latex film by ultrafine calcium carbonate, Journal of applied polymer science 87(6) (2003) 982-985.

[25] S. Manroshan, A. Baharin, Effect of nanosized calcium carbonate on the mechanical properties of latex films, Journal of Applied Polymer Science 96(5) (2005) 1550-1556.

[26] X. Li, Z. Li, Y. Xia, Test and calculation of the carbon black reinforcement effect on the hyper-elastic properties of tire rubbers, Rubber Chemistry and Technology 88(1) (2015) 98-116.

[27] L. Yang, V. Shim, C. Lim, A visco-hyperelastic approach to modelling the constitutive behaviour of rubber, International Journal of Impact Engineering 24(6-7) (2000) 545-560.

[28] Y. Bai, C. Liu, G. Huang, W. Li, S. Feng, A Hyper-Viscoelastic Constitutive Model for Polyurea under Uniaxial Compressive Loading, Polymers 8(4) (2016) 133.

[29] L.-D.K.U.s. Manual, I. Volume, Version 971, Livermore Software Technology Corporation 7374 (2007) 354.

[30] K. Spranghers, D. Kakogiannis, J. Ndambi, D. Lecompte, H. Sol, Deformation measurements of blast loaded plates using digital image correlation and high-speed photography, EPJ Web of Conferences, EDP Sciences, 2010, p. 12006.

[31] M. Ghalami-Choobar, M. Sadighi, Investigation of high velocity impact of cylindrical projectile on sandwich panels with fiber-metal laminates skins and polyurethane core, Aerospace Science and Technology 32(1) (2014) 142-152.

[32] A. Khodadadi, G. Liaghat, H. Ahmadi, A.R. Bahramian, Y. Anani, O. Razmkhah, S. Asemeni, Numerical and experimental study of impact on hyperelastic rubber panels, Iranian Polymer Journal (2018) 113-122. 